Review

\title{
Multifunctional Iron Oxide Nanoparticles for Diagnostics, Therapy and Macromolecule Delivery
}

\author{
Swee Kuan Yen ${ }^{1}$, Parasuraman Padmanabhan ${ }^{2}$, Subramanian Tamil Selvan ${ }^{1,3} \bowtie$ \\ 1. Institute of Materials Research and Engineering (IMRE), A*STAR (Agency for Science, Technology and Research), 3 Research Link, \\ Singapore 117602 \\ 2. The Lee Kong Chian School of Medicine, Nanyang Technological University, 50 Nanyang Drive, Research Techno Plaza, Level 4, \\ X-Frontier Block, Singapore 637553. \\ 3. National University of Singapore, Division of Biomedical Engineering, Faculty of Engineering, 7 Engineering Drive 1 Singapore 117576.
}

$\square$ Corresponding author: Subramanian Tamil Selvan, Ph.D., Institute of Materials Research and Engineering (IMRE), 3 Research Link, Singapore 117602. Tel: 65-6874-5249; Fax: 65-6774-4657; E-mail: subramaniant@imre.a-star.edu.sg; biests@nus.edu.sg.

(c) Ivyspring International Publisher. This is an open-access article distributed under the terms of the Creative Commons License (http://creativecommons.org/ licenses/by-nc-nd/3.0/). Reproduction is permitted for personal, noncommercial use, provided that the article is in whole, unmodified, and properly cited.

Received: 2012.12.07; Accepted: 2012.12.18; Published: 2013.12.07

\begin{abstract}
In recent years, multifunctional nanoparticles (NPs) consisting of either metal (e.g. Au), or magnetic NP (e.g. iron oxide) with other fluorescent components such as quantum dots (QDs) or organic dyes have been emerging as versatile candidate systems for cancer diagnosis, therapy, and macromolecule delivery such as micro ribonucleic acid (microRNA). This review intends to highlight the recent advances in the synthesis and application of multifunctional NPs (mainly iron oxide) in theranostics, an area used to combine therapeutics and diagnostics. The recent applications of NPs in miRNA delivery are also reviewed.
\end{abstract}

Key words: nanoparticles; iron oxide; gold; contrast agents; MRI; optical imaging; miRNA delivery; theranostics.

\section{Introduction}

The research on superparamagnetic iron oxide nanoparticles (SPIONs) has been growing exponentially over the last several years. The field continues to drive in the direction of biomedical applications, especially molecular therapeutics by exploiting the immense qualities of SPIONs [1]. This includes the distinctive controllable properties such as size, shape, magnetism, crystallinity and flexibility in fabricating multifunctional SPIONs with fluorescence, targeting ligands, drugs etc, thanks to the advancements in the syntheses and functionalization techniques developed hitherto. There are some excellent synthetic methods in prior arts on the formation of superparamagnetic magnetite $\left(\mathrm{Fe}_{3} \mathrm{O}_{4}\right)$ and maghemite $\left(\gamma-\mathrm{Fe}_{2} \mathrm{O}_{3}\right)$ SPIONs, with size control, narrow distribution, water solubility and surface functionalization [2-7]. The co-precipitation method is a conventional synthetic paradigm where $\mathrm{Fe}(\mathrm{II})$ and $\mathrm{Fe}(\mathrm{III})$ salts are co-precipitated in a basic solution in the presence of coating materials such as polymer or dextran (or its derivatives). Although the resulted iron oxide nanoparticles (NPs) are larger in size (ca. $100 \mathrm{~nm}$ ) and partially crystalline, the particles are readily water soluble where their surfaces are directly functionalized. Alternatively, thermal decomposition method using precursors such as $\mathrm{Fe}(\mathrm{CO})_{5}, \mathrm{Fe}(\text { Stearate)})_{2}$, with high boiling solvents (octadecene, benzyl ether) and surfactants/ligands (oleic acid, oleylamine) can be used to synthesize smaller sized hydrophobic SPIONs (5-10 nm). In order to impart the SPIONs with water solubility for biomedical applications, water-oil microemulsion method can be employed as a reaction medium for coating a hydrophilic ligand (e.g. silica, peptides) on the hydrophobic surface. 


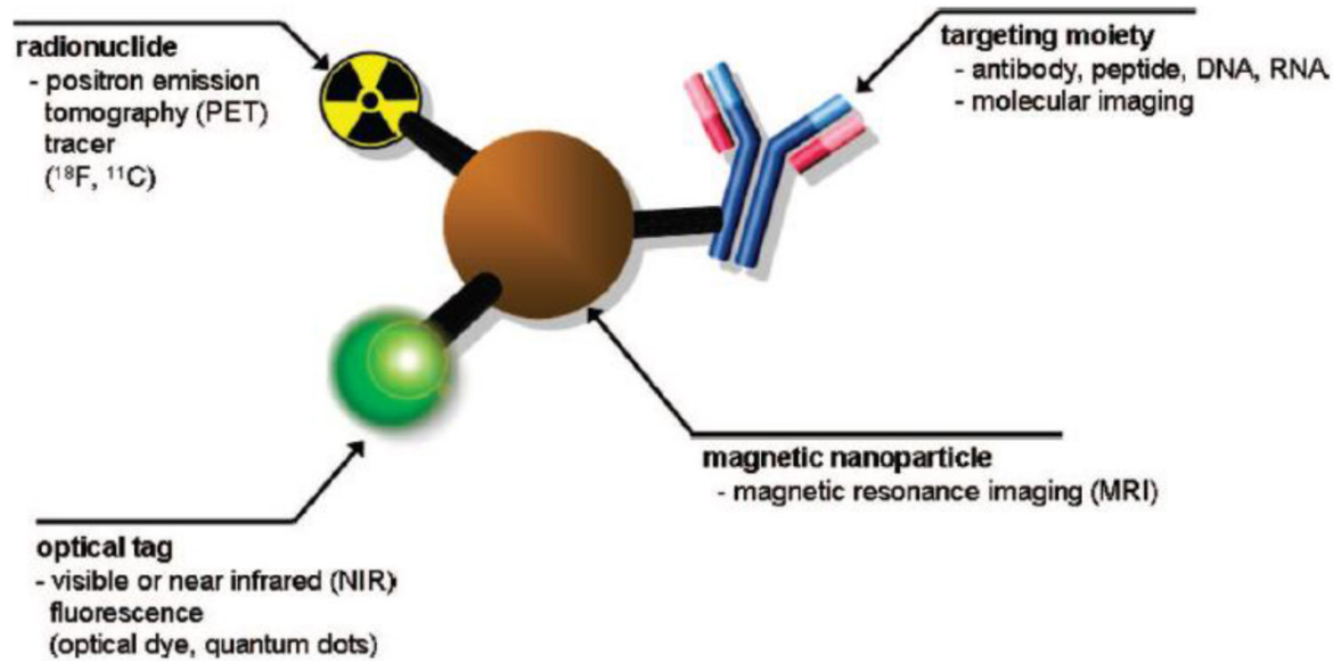

Figure I. Schematic of a multimodal imaging probe. A magnetic nanoparticle, radionuclide, optical tag and targeting moiety are integrated into a single system, which acts as a multimodal molecular imaging platform. Reproduced with permission from Ref. [2]. Copyright (2008) American Chemical Society.

SPIONs have been extensively studied as $\mathrm{T}_{2}$ contrast agents in magnetic resonance imaging (MRI) because the negative contrast (darkness) in phantom images can be enhanced by $T_{2}$ relaxivity of water protons. SPIONs due to their non-toxicity could potentially be used as non-invasive diagnostic tools. Multiple functionalities such as magnetic, optical, radionuclide and specific targeting ligands can be integrated into a single system, which has gained deeper insights in multimodal imaging (Figure 1) [2]. Multifunctional SPIONs have also been used as drug-delivery and photodynamic therapy agents in the emerging area of theranostics. Some excellent review articles appeared in the literature in the area of multifunctional nanoparticles (NPs) $[3,8]$.

This review focuses mainly on the recent advances in multifunctional SPIONs for diagnostics, therapy and macromolecule delivery. We discuss several strategies for the design of molecular imaging probes with an emphasis on MRI, optical imaging/MRI, SPIONs for drug delivery, hyperthermia, and RNA delivery by SPIONs.

\section{SPIONs for MRI}

MRI is one of the non-invasive medical diagnostic techniques. The MR images of normal and abnormal tissues are difficult to differentiate; therefore, specific exogenous contrast agents are needed to increase the contrast and obtain higher resolution and sensitivity. SPIONs have been extensively used as contrast agents for MR imaging of reticuloendothelial targeting and tumors targeting probes. There are two criteria of SPIONs as MR imaging probes: (i) Magnetism: The superparamagnetic SPIONs exhibit a high magnetization when an external magnetic field is applied; the magnetization becomes zero when the ex- ternal magnetic field is removed. They provide the negative (dark) contrast by enhancing $T_{2} / T_{2}{ }^{*}$ relaxivity of water protons for MRI. SPIONs are generally the core or dopants in the nanoparticles [1]. (ii) Well-developed surface coating and functionality: This includes introducing targeting ligands such as proteins, peptides, antibodies, polymers, carbohydrates, aptamers, DNA, RNA, oligosaccharides onto or surrounding magnetic nanoparticles to improve the target-specific tumors. Other uncommon targeting moieties are radionuclides, organic salts/ionic liquids and graphites. The good water solubility of SPIONs is important to avoid the aggregation. It is also important to modulate the water soluble SPIONs and the coating thickness for $r_{1} / r_{2}$ relaxations in MRI. Different thickness of coating materials will affect $T_{2}$ relaxivity of water protons from magnetic field. In the following subsection, we provide some recent examples of different ligands-conjugated MRI nanoprobes.

\section{I. Peptide-conjugated MRI nanoprobes}

Peptides are one of the commonly employed targeting ligands for cell labeling applications. RGD peptides, cell penetrating and nuclear localizing signaling peptides are mostly used to coat the NPs for increased cell uptake via receptor-mediated endocytosis.

Using electrostatic interactions, peptides with positive charges have been bound to negatively charged dextran- modified SPIONs under physiological conditions [9]. The unbound peptides were separated by using the ultra-filtration device and followed by centrifugation. The SPIONs with a tag of amino acids had the specific-recognition as well as the cell transport units. Before proceeding to the selective target binding in vitro and in vivo, the team further examined the stability tests under protein-containing 
conditions in human blood.

SPION-Tat peptide conjugates were used to improve intracellular magnetic labeling of different target cells such as murine lymphocytes, human natural killer (NK) cells and HeLa cells [10]. The peptides had HIV-Tat(FITC - fluorescent isothiocyanate) with the sequence Gly-Gly-Cys-Gly-Arg-Lys-Lys-Arg-Arg-GlnArg-Arg-Arg-Lys-(FITC)- $\mathrm{NH}_{2}$ (the italicized amino acids referred to residues $48-57$ of the tat protein). The SPIONs were cross-linked with $N$-succinimidyl-3(2-pyridyldithio) propionate, and Tat(FITC) peptides were attached to sulfhydryl groups of SPIONs at $\mathrm{pH}$ 7.4 through a disulfide exchange reaction. The conjugated SPIONs had a mean particle size of $41 \mathrm{~nm}$ and showed 100 fold more efficient internalization into lymphocytes in comparison with unmodified particles.

A novel protease-specific nanosensor for MRI was reported [11]. The SPIONs were electrostatically stabilized with a peptide and a methyl-polyethylene glycol polymer (mPEG, molecular weight 5000). The peptide consisted of a cleavage domain with the enzyme and positively charged, arginine-rich coupling domain with a linker sequence. The hydrodynamic diameter of matrix metalloproteinase 9 (MMP)-activatable protease-specific SPIONs was 25 $\mathrm{nm}$. Upon activation of SPIONs, the peptide-mPEG was cleaved, resulting in aggregation and increased $\mathrm{T}_{2}{ }^{*}$-relaxivity.

In another interesting work, Xie et al. synthesized SPIONs $(<10 \mathrm{~nm})$ coated with a ligand, 4-methylcatechol (MC) and attached a peptide, c(RGDyK) via the Mannich reaction to couple $\mathrm{NH}_{2}$-terminated peptide with SPIONs for specific targeting to integrin $\alpha_{v} \beta_{3}$-rich human glioblastoma (U87MG) tumor cells [12]. Due to the multivalent binding, the $\mathrm{c}(\mathrm{RGDyK})-\mathrm{MC}-\mathrm{Fe}_{3} \mathrm{O}_{4}$ nanoparticles (NPs) showed an increased cellular uptake compared to free RGD peptides. Thus the peptide -conjugated SPIONs have shown great potential as contrast agents for in vivo tumor detection using MRI (Figure 2).

(a)
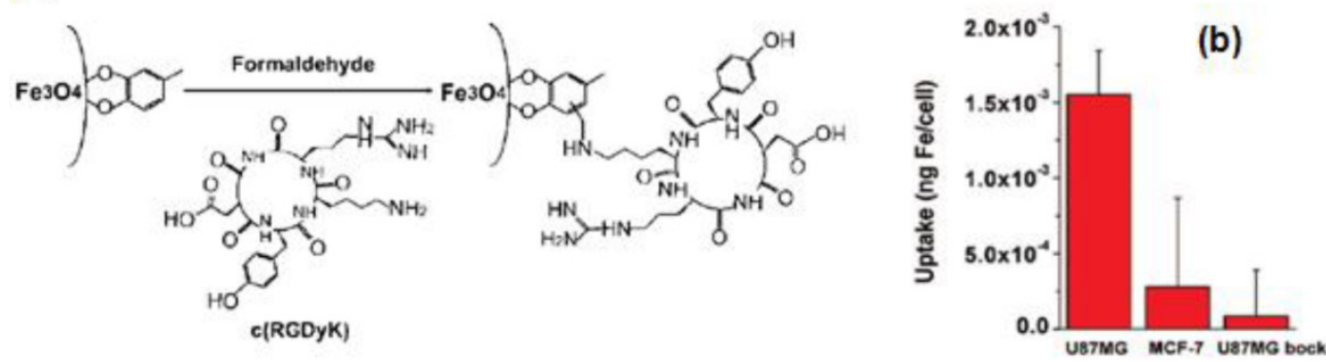

(c)

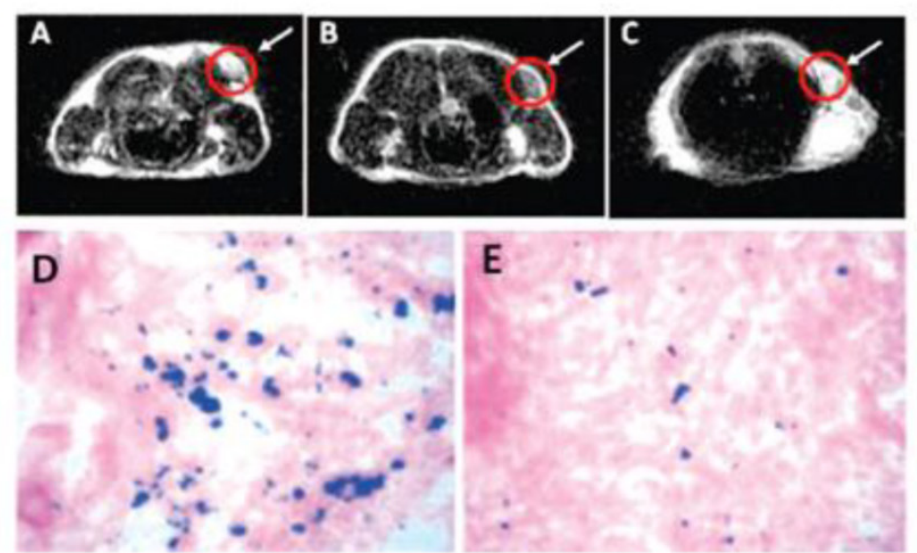

Figure 2. (a) Coupling $c(R G D y K)$ peptide to $\mathrm{Fe}_{3} \mathrm{O}_{4}$ NPs. (b) Cell uptake of $\mathrm{c}(\mathrm{RGDyK})-\mathrm{MC}-\mathrm{Fe}_{3} \mathrm{O}_{4}$ NPs by U87MG, MCF-7 and U87MG $+\mathrm{c}(\mathrm{RGDyK})$ block. (c) MRI of the cross section of the U87MG tumors implanted in mice: (A) without NPs, (B) with the injection of $300 \mu \mathrm{gg}$ of $c(\mathrm{RGDyK})-\mathrm{MC}$-Fe $\mathrm{O}_{3} \mathrm{O}_{4} \mathrm{NPs}$, and (C) with the injection of $c(R G D y K)-M C-F_{3} \mathrm{O}_{4} \mathrm{NPs}$ and blocking dose of $c(R G D y K)$; Prussian blue staining of U87MG tumors in the presence of (D) $c(\mathrm{RGDyK})-\mathrm{MC}-\mathrm{Fe}_{3} \mathrm{O}_{4} \mathrm{NPs}$ and $(\mathrm{E}) \mathrm{c}(\mathrm{RGDyK})-\mathrm{MC}-\mathrm{Fe}_{3} \mathrm{O}_{4} \mathrm{NPs}$ plus blocking dose of $\mathrm{c}(\mathrm{RGDyK})$. Reproduced with permission from Ref. [12]. Copyright (2008) American Chemical Society. 

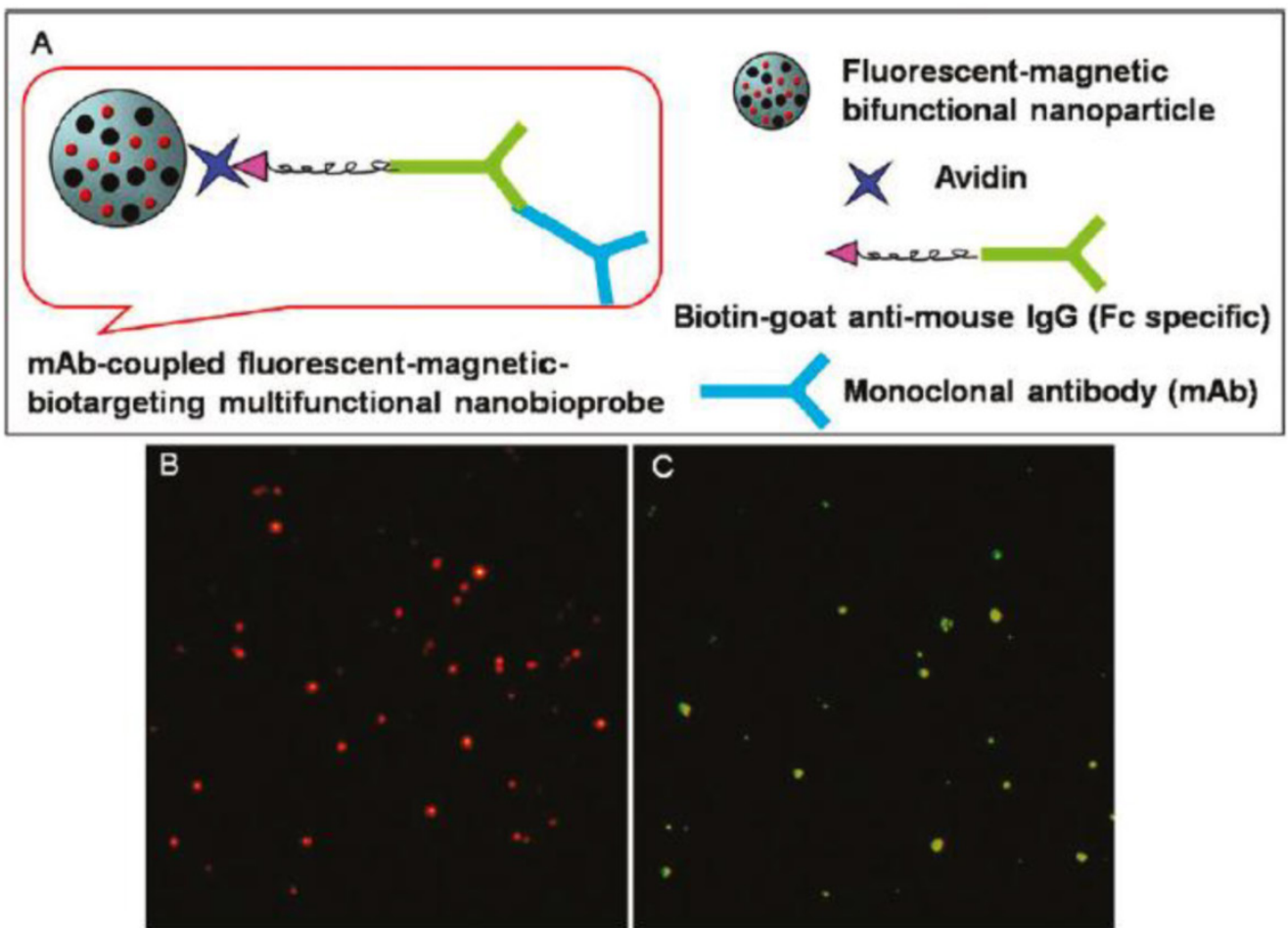

Figure 3. (A) Schematic drawing of an mAb-coupled fluorescent-magnetic-biotargeting multifunctional nanobioprobes (FMBMN). Flurescent-magnetic bifunctional NPs were covalently coupled with avidin. They were then coated with biotinylated goat anti-mouse IgG (Fc specific) via the biotin-avidin interaction. Mouse monoclonal antibody $(\mathrm{mAb})$ was then attached to the NPs via the binding to the goat antibody. (B, C) Fluorescence microscopic images of anti-CD3 mAb-coupled red nanobioprobes (B) and anti-PSMA mAb-coupled yellow nanobioprobes (C). Here each fluorescent dot came from single mAb-coupled FMBMN containing multiple QDs. Reproduced with permission from Ref. [16]. Copyright (20II) American Chemical Society.

\subsection{Antibody-conjugated MRI nanoprobes}

Antibodies are proteins with special Y- shapes. They can specifically recognize and bind to antigens in both the recognition phase (cellular receptors) and during the effectors phase (synthesis and secretion) of humoral immunity. Active targeting by monoclonal antibodies (mAbs) combined with SPION is a promising technology for magnetic resonance imaging.

Antibody-SPION conjugates can also be prepared by ionic interactions between the two entities through the immobilization of non-modified antibodies. Three antibodies (Immunoglobulin G class) with very different isoelectric points (against peroxidase, carcinoembryonic antigen, and human chorionic gonadotropin hormone) were used to prove the general applicability of the strategy [13]. Polymer coated SPIONs were modified with antibodies $(\mathrm{Ab})$ against human epithelial growth factor receptor 2 (anti-HER2 or anti-HER2/neu), forming SPION-Ab. HER2 is a cell membrane protein that is over-expressed in several types of human cancer cells. SPION-Ab conjugates were used to separate ca. $80 \%$ of human breast cancer SK-BR3 cells that were spiked in $1 \mathrm{~mL}$ of fresh human whole blood [14].

Cheon and coworkers have fabricated multifunctional magnetic nanocrystals with a cancer-targeting antibody, Herceptin as an MRI nano- probe for the diagnosis of various types of cancer in vitro and in vivo [15]. Pang and coworkers expanded the application of the monoclonal antibody (mAb) fluorescent-magnetic-biotargeting multifunctional nanobioprobes (FMBMNs) for detecting and isolating multiple types of tumor cells such as leukemia cells and prostate cancer cells with a capture efficiency of over $96 \%$ (Figure 3) [16]. The specific and sensitive detection, and rapid separation of a small number of the above-mentioned two types of cells in a large population of cultured normal cells (about $0.01 \%$ tumor cells) were achieved inexpensively without any sample pretreatment before cell analysis. Hence, Herceptin and mAb - conjugated magnetic NPs can be used as effectively for tumor imaging and separation studies.

\subsection{Polymer-conjugated MRI nanoprobes}

Polymer-functionalized and in particular, PEGylated SPIONs $[17,18]$ can provide improved biocompatibility and colloidal stability. The hydrophobic oleic acid-coated SPIONs were exchanged with a mixture of poly- $\mathrm{N}$-isopropylacrylamide (PNIPAAm) and biotinylated polymer to make them water soluble and finally bioconjugated with streptavidin [19].

Hatton and coworkers have synthesized two types of stimuli-responsive Janus magnetic NPs (MNPs) $(5 \mathrm{~nm})$ coated on one side with a 
pH-dependent but temperature-independent polymer (PAA), and functionalized on the other side with a second polymer that is either $\mathrm{pH}$-independent (PSS$\mathrm{Na}$ ) or temperature-dependent (PNIPAM) [20]. The Janus MNPs (Janus-PSSNa or Janus-PNIPAM particles) can be dispersed separately at high $\mathrm{pH}$ values or low temperature and self-assembled at low $\mathrm{pH}$ values or at temperatures greater than $31^{\circ} \mathrm{C}$. A polyelectrolyte (polysodium-4-styrene sulfonate, PSSS) stabilized MNPs were aligned in linear arrays by an external field [21]. Three composites were prepared, with a range of $\mathrm{Fe} /$ monomer ratios of 1:2 (PSSS-Mag1), 3:1 (PSSSMag2 PSSSMag2), and 6:1 (PSSS-Mag3). The magnetic fluids had good biocompatibility and useful for in vivo MRI (Figure 4). Magnetic glycol-nanoparticles (MGNP) based nanosensor system bearing carbohydrates as the ligands was reported [22]. The MNPs could not only detect and differentiate cancer cells but also could quantify their carbohydrate binding abilities by MRI. The system distinguished a range of cells with different metastatic potential and malignant versus normal cells based on "MRI signature".

The application of SPIONs as $T_{1}$ contrast agents was also explored. Small-sized SPIONs $(<4 \mathrm{~nm}$ : 1.5, 2.2 and $3 \mathrm{~nm}$ ) were synthesized via the thermal decomposition of iron-oleate complex in the presence of oleyl alcohol. The hydrophobic NPs became water-dispersible after capping with poly(ethylene glycol)-derivatized phosphine oxide (PO-PEG) ligands. The 3nm-sized iron oxide@PO-PEG NPs gave no toxic response with Fe concentration up to $100 \mu \mathrm{g} / \mathrm{mL}$ in MTT cell proliferation assay. These NPs exhibited a high $\mathrm{r}_{1}$ relaxivity of $4.78 \mathrm{mM}^{-1} \mathrm{~s}^{-1}$ and low $\mathrm{r}_{2} / \mathrm{r}_{1}$ ratio of 6.12, and regarded as efficient $\mathrm{T}_{1}$ contrast agents (Figure 5). Furthermore, the NPs showed a longer circulation time than the clinically used gadolinium complex-based contrast agent [23].

Block polymers have been used as coating materials for SPIONs. The typical block copolymers used are poly(trimethylammonium ethylacrylate methyl sulfate)- $b$-poly(acrylamide) with molecular weights 5000-b-30000 gmol $^{-1}$ and 110000- $b-30000$ gmol $^{-1}$. Superparamagnetic SPIONs (maghemite $\gamma-\mathrm{Fe}_{2} \mathrm{O}_{3}$ ) of 6.3 $\mathrm{nm}$ diameter were electrostatically coated by cationic-neutral copolymers. These MNPs showed a better contrast in MRI compared to single NPs [24]. A radical polymerization of monomer $\mathrm{N}, \mathrm{N}$-dimethylacrylamide (DMMAm) was done in solution with maghemite SPIONs and yielded $\operatorname{poly}(\mathrm{N}, \mathrm{N}-$ dimethylacrylamide) (PDMAAm)-coated SPIONs. The uncoated and PDMAAm-coated SPIONs have been used to label the rat and human bone marrow mesenchymal stem cells (MSCs) and Endorem (dextran-modified SPIONs) as a control. PDMAAm-modified SPIONs showed a higher efficiency of intracellular uptake into human cells and higher $T_{2}$ relaxivity compared to Endorem and unmodified SPIONs. PDMAAm-modified SPIONs -labeled rMSCs implanted in a rat brain showed better resolution in vivo MRI in comparison with Endorem-labeled cells (Figure 6) [25].

SPIONs were also coated with the protein- or cell-resistant polymer, poly(TMSMA-r-PEGMA) as an MRI agent for in vivo cancer imaging (Figure 7) [26]. The SPIONs did not have any targeting ligands on their surface and yet they may potentially be applied for cancer diagnosis in vivo. These studies demonstrate that polymer - coated SPIONs can be conveniently employed for in vivo cancer imaging. However, it necessitates the toxicity and clearance studies.

(A)
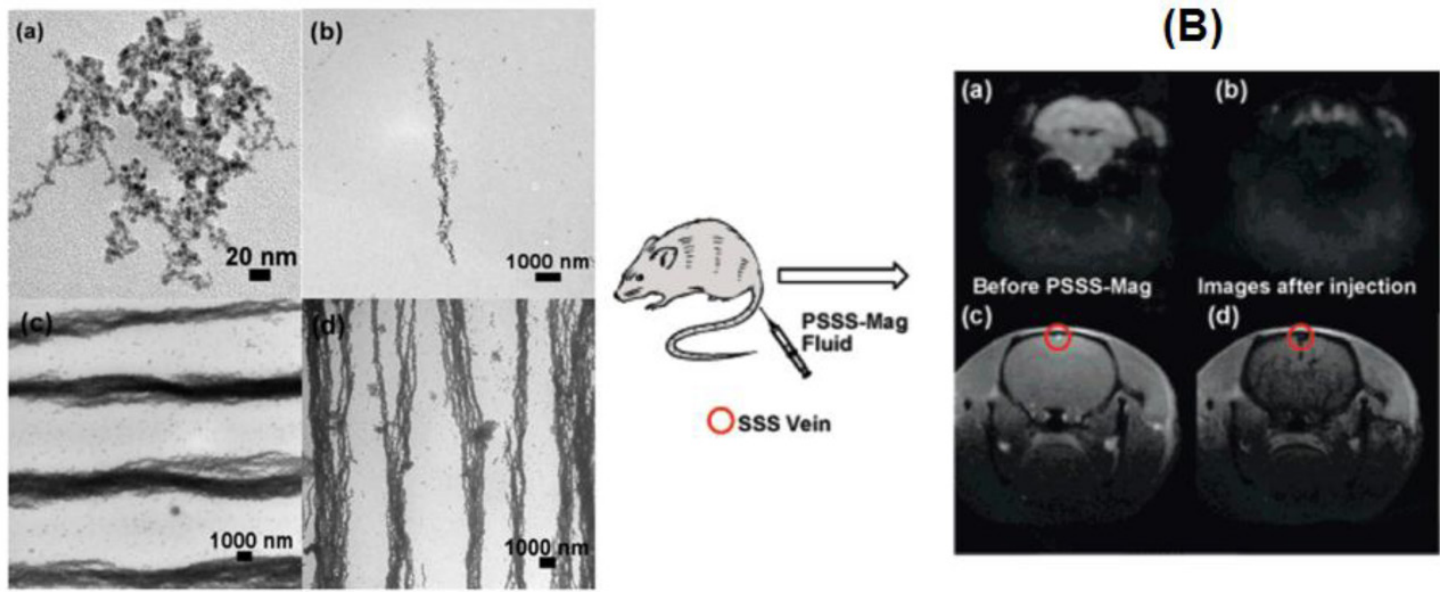

Figure 4. (A) TEM images of (a) PSSS-MagI sample dried without magnetic field of (b) PSSS-Magl, (c) PSSS-Mag2, and (d) PSSS-Mag3 samples upon drying in a $0.5 \mathrm{~T}$ magnetic field. (B) Echo planar image (EPI) of mouse brain (a) before and (b) as PSSS-Magl passes through; Fast Low Angle Shot (FLASH) image of mouse brain (c) before and (d) as PSSS-Magl passes through. Reproduced with permission from Ref. [2I]. Copyright (2008) American Chemical Society. 
a)

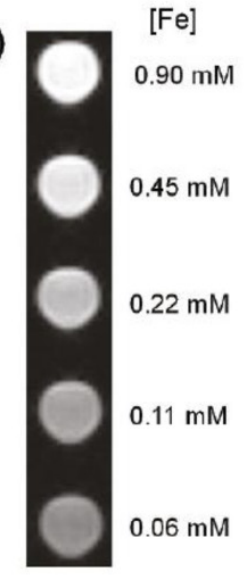

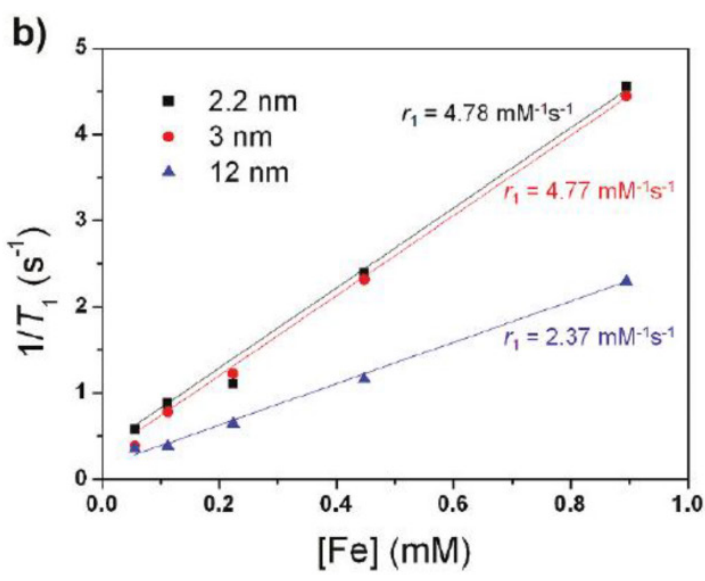

c)

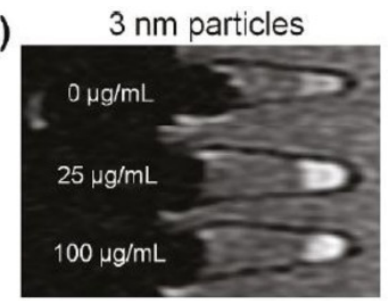

d)

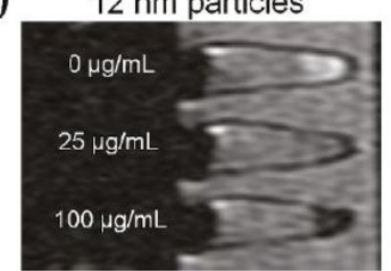

Figure 5. (a) $T_{1}$ weighted MR images of $3 \mathrm{~nm}$-sized SPIONs. (b) Plot of $\mathrm{I} / T_{1}$ over Fe concentration of SPIONs with diameters of $2.2 \mathrm{~nm}, 3 \mathrm{~nm}$ and $\mathrm{I} 2 \mathrm{~nm}$. The slope indicates the specific relaxivity ( $\mathrm{rl}$ ). (c, d) $T_{1}$ weighted MR images of MCF-7 cell pellets after $24 \mathrm{~h}$ incubation with SPIONs with diameters of (c) $3 \mathrm{~nm}$ and (d) $12 \mathrm{~nm}$. Reproduced with permission from Ref. [23]. Copyright (20II) American Chemical Society.

(a)

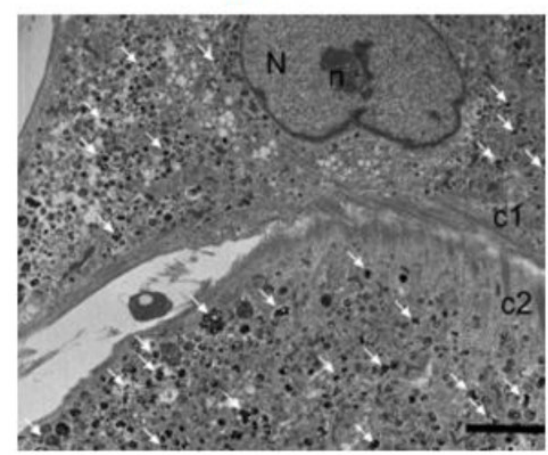

(b)

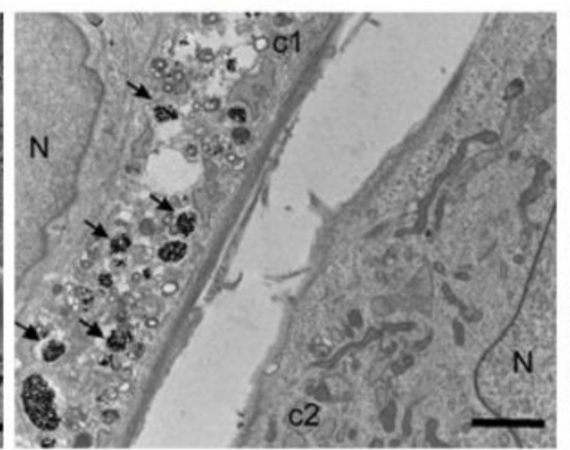

(c)

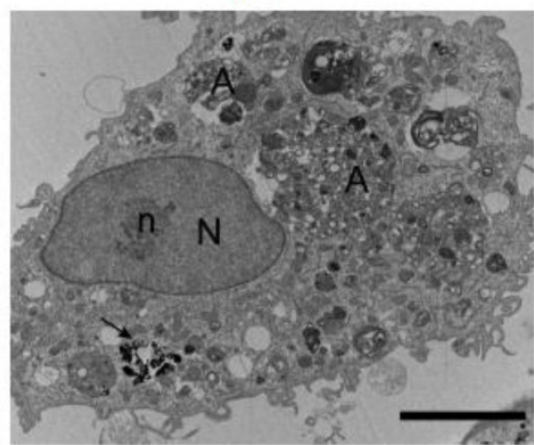

Figure 6. TEM micrographs of $r M S C$ s labeled with (a) PDMAAm-coated $\gamma-\mathrm{Fe}_{2} \mathrm{O}_{3} \mathrm{NPs}$, (b) Endorem, and (c) uncoated $\gamma$ - $\mathrm{Fe}_{2} \mathrm{O}_{3}$. Arrows indicate $\mathrm{NPs}$ inside the endosomes. A, autophagosome; N, nucleus; $\mathrm{n}$, nucleolus; $\mathrm{cl}$ and c2, cell I and cell 2, respectively. Scale bar: a, c, $500 \mathrm{~nm}$; b, $200 \mathrm{~nm}$. Reproduced with permission from Ref. [25]. Copyright (2009) American Chemical Society.

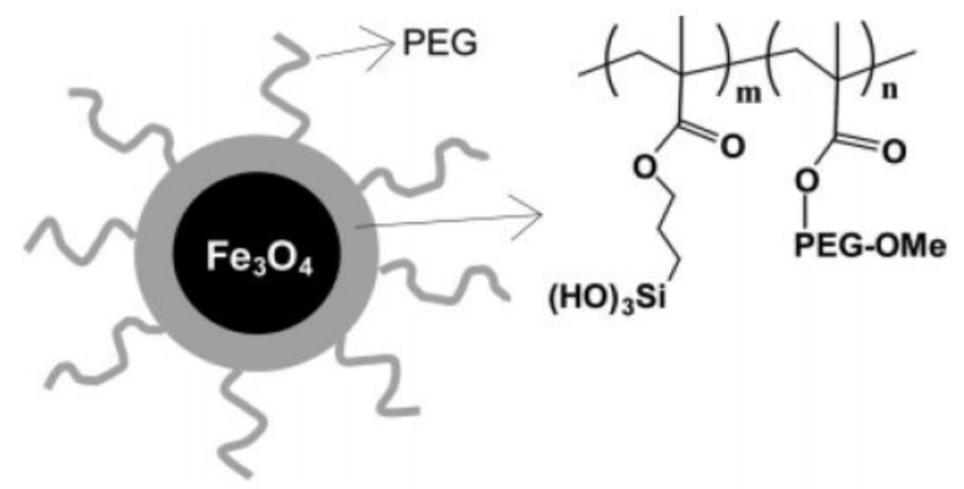

\section{poly(TMSMA-r-PEGMA)@SPION}

Figure 7. Polymer-coated superparamagnetic SPION and chemical structure of the PEG-silane copolymer, poly(TMSMA- $\gamma$-PEGMA). Reproduced with permission from Ref. [26]. Copyright (2006) American Chemical Society.

\subsection{Carbohydrates-conjugated MRI nano- probes}

Valero et al. demonstrated the synthesis of carbohydrate-coated SPIONs as MRI nanoprobes [27]. They showed the pH-driven assembly-disassembly natural process that occurred in apoferritin and found it effective for encapsulating maghemite SPIONs of 4 and $6 \mathrm{~nm}$. The SPIONs were further functionalized with two carbohydrates, $N$-acetyl-D-glucosamine and D-mannose vinyl sulfone derivatives. The representative mouse brain images acquired before and $120 \mathrm{~s}$ after administration of contrast agents and corresponding regional cerebral blood volume maps 
(rCBV) maps are shown in Figure 8. Similar to Endorem, post-contrast images and rCBV maps obtained with Apomaghemite samples depicted very well the space arrangement of cerebral vessels. This study confirmed that Apomaghemite SPIONs could serve as promising contrast agents. Furthermore, the carbohydrate-functionalized Apomaghemite NPs retained their recognition abilities, as demonstrated by the strong affinity with their corresponding carbohydrate-binding lectins.

Monosaccharides have been used as targeting ligands for sensing proteins and bacteria. A versatile approach for the immobilization of unmodified monosaccharides onto SPIONs was reported by Yan team [28]. Covalent coupling of D-mannose onto SPIONs by using $\mathrm{CH}$ insertion reaction of photochemically activated phosphate-functionalized perfluorophenylazides (PFPAs) resulted in glyco-NPs. The surface-bound D-mannose had mannose-specific receptor and showed the recognition ability toward Concanavalin A and Escherichia coli strain ORN178. These studies imply that the carbohydrate-conjugated SPIONs might be useful in clinical diagnosis, sensing and decontamination.

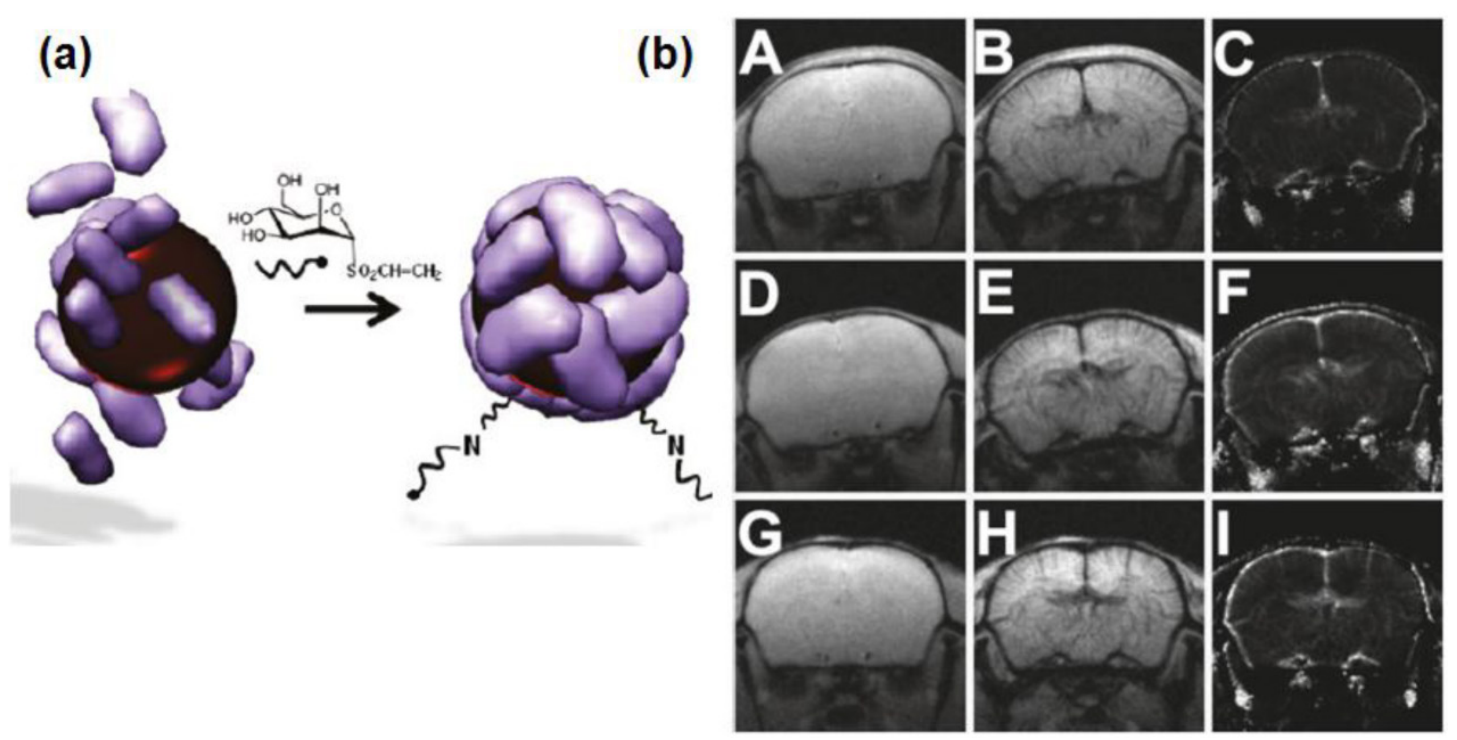

Figure 8. (a) Glycosylation of Apomaghemite NPs by reaction of N-acetyl-D-glucosamine or D-mannose vinyl sulfone derivaties with the amine group naturally present in the Apomaghemite NPs to make them recognizable by lectins. (b) Representative mouse brain images acquired before and I $20 \mathrm{~s}$ after administration of contrast agents and corresponding rCBV maps. Upper line: Precontrast (A), postcontrast (B), and rCBV map (C) obtained with APOMAG-4. Middle line: Precontrast $(\mathrm{D})$, postcontrast $(\mathrm{E})$, and rCBV map $(\mathrm{F})$ obtained with APOMAG-6. Lower line: Precontrast $(\mathrm{G})$, postcontrast $(\mathrm{H})$, and rCBV map (I) obtained with Endorem. Reproduced with permission from Ref. [27]. Copyright (20II) American Chemical Society.

\subsection{Aptamer-conjugated MRI nanoprobes}

Aptamers are single-stranded oligonucleotides, which can recognize their targets with excellent specificity and high affinity. They are rival candidates to antibodies, and emerge as potential conjugation platform for a variety of NPs. Aptamer-conjugated magnetic NPs have been used for a variety of applications, particularly, as magnetic relaxation switches for the detection of molecular interactions [29] and for magnetic extraction of targeted cells in a variety of mixtures [30,31] and also for cancer cell separation and fluorescent labeling with SPION-plasmonic Au bimodal NPs [32].

Jan et. al. have designed a CG-rich duplex containing prostate-specific membrane antigen (PSMA) aptamer-conjugated thermally cross-linked superparamagnetic IONs via a hybridization method (Apt-hybr-TCL-SPION) for prostate cancer-specific nanotheranostic agents [33]. The Apt-hybr-TCL-
SPION thus further loaded with doxorubicin (Dox) molecules through the intercalation to the CG-rich duplex containing PSMA aptamer as well as electrostatic interactions. MRI results showed that the Apt-hybr-TCL-SPION preferential binding towards target prostate cancer cells (LNCaP) both in vitro and in vivo. The resulting Dox loaded Apt-hybr-TLC-SPION gave the selective drug-delivery efficacy in the targeted prostate cancer cells xenograft mouse model. Wang et. al. also demonstrated the conjugation of aptamers (A10 RNA) to SPIONs via gel electrophoresis [34]. They showed that the A10 aptamer physically conjugated with Dox and the Dox was released in a controlled fashion to PSMA expressing PCa cells. The aptamer-SION bioconjugates gave the efficacy as targeted imaging agents using MRI. Lu et. al. also combined aptamer technology with SPIONs using specifically method to develop adenosine DNA aptamer-functionalized SPIONs [35]. The surface of SPION was functionalized with 
$\mathrm{N}$-succinimidyl 3-(2-pyridyldithio)-propionate (SPDP) and further coupled to thiol-modified DNA ( $3^{\prime}$ Adap or 5' Adap). $T_{2}$-weighted MR images showed the quantitative analysis performance with different adenosine concentrations. While the adenosine concentration increased, the brightness of the $T_{2}$ image also increased.

SPIONs, functionalized with aptamer were used for MRI detection of human $\alpha$-thrombin protein (Figure 9) [36]. The contrast agent was designed based on the assembly of the aptamer functionalized SPIONs in the presence of thrombin. The system was specific to thrombin and a detectable change in MRI signal was observed at $25 \mathrm{nM}$ thrombin in human serum. Changes were not observed with other control analytes such as streptavidin and bovine serum albumin or with inactive aptamer functionalized NPs. These studies demonstrate that aptamer - conjugated SPIONs can be used as potential theranostics agents.

\subsection{Other functionalization methods}

DNA has been used as a template to electrostatically assemble $\mathrm{Fe}_{2} \mathrm{O}_{3}$ MNPs while retaining its biochemical recognition properties [37]. Upon stretching, the templated DNA could be digested by the BamH1 restriction enzyme.

Graphite-coated magnetic FeCo core-shell nanocrystals for few-cells enrichment and detection were reported [38]. FeCo nanocrystals were synthesized by a chemical vapor deposition method and became water soluble via coating the graphite shell with DSPE-PEG-NH ${ }_{2}$ and C18-PMH-mPEG polymers, while preventing the magnetic core from oxidation and degradation. These functionalized MNPs were stable and suitable for significant biological applications, such as cell staining, manipulation, cancer cell separation, enrichment and detection. The MNPs -stained cells showed directed motions under external magnetic manipulation.

Ionic liquids are considered as organic solvents with high polarity and a pre-organized solvent structure. Crystalline NPs can be synthesized by using ionic liquid at ambient temperature [39]. Warner and coworkers have developed magnetic NPs coated with a group of uniform materials based on organic salts by using in-situ ion exchange water-in-oil (w/o) microemulsion approach [40]. These MNPs could potentially be applied in drug delivery, MRI and protein separations.

In another interesting work, Louie and coworkers have reported the synthesis of a reversible $T_{2}$ contrast agent that is capable of modulating the relaxation time in response to light irradiation [41]. A spiropyran (SP) derivative that changes conformation between hydrophilic and hydrophobic isomers in response to light, has been covalently attached to dextran sulfate coated iron oxide nanoparticles (ADIO). The light induced reversible aggregation of MNPs has been found to modulate the $T_{2}$ relaxation time (Figure 10). (a)

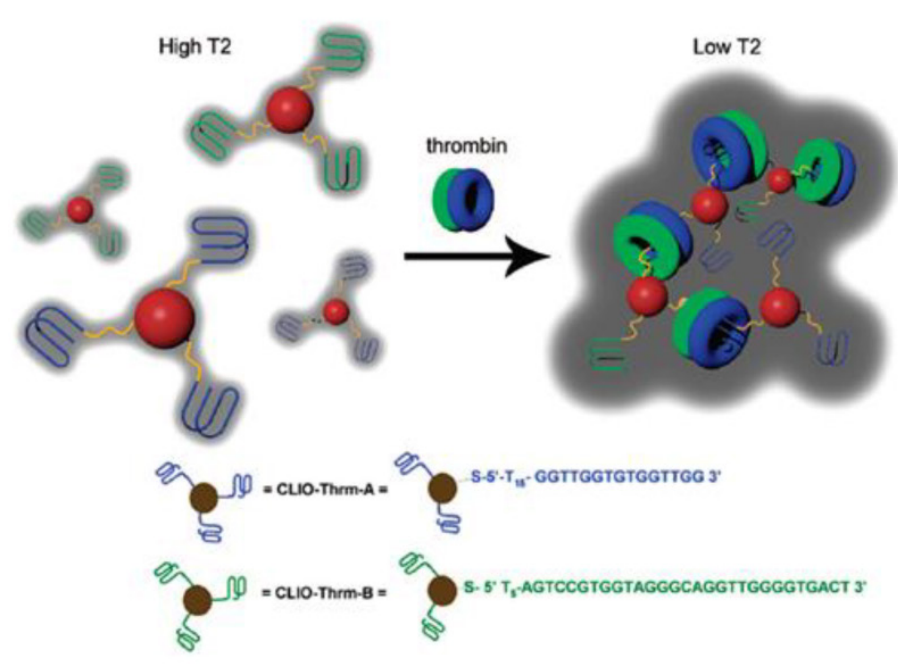

(b)

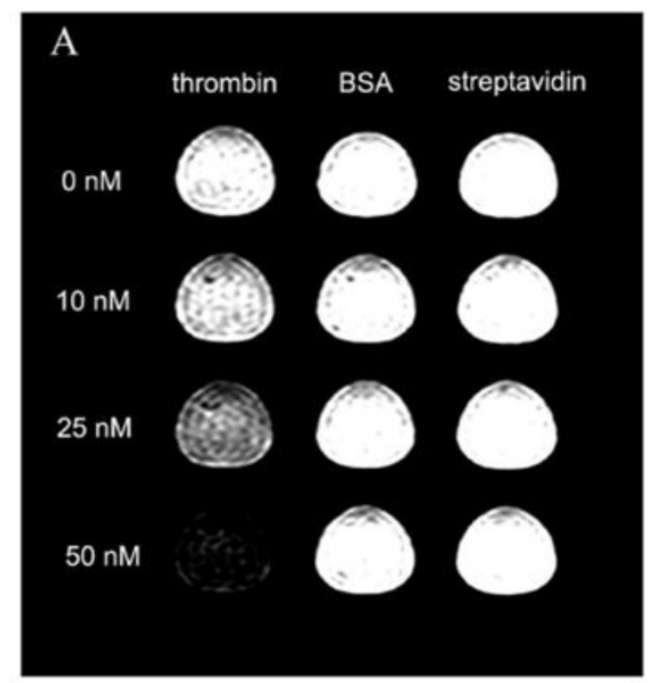

Figure 9. (a) The CLIO NPs (shown as red spheres) have been modified with either Thrm-A, A DNA aptamer (shown as blue lines) that binds to fibrinogen-recognition exosite of thrombin, or Thrm-B, a DNA aptamer (shown as green lines) that binds to the heparin-binding exosite of thrombin. Addition of thrombin consisting of both fibrinogen (as blue donut) and heparin (as green donuts) exosites resulted in aggregation of CLIO NP assembly, reducing the T2 relaxation time. The DNA sequences are shown at the bottom. The drawing is not to scale. (b) Contrast change in T2-weighted MR image in I:I CLIO-Thrm-A and CLIO-Thrm-B mixture with 0, 10, 25 and $50 \mathrm{nM}$ thrombin (first column), BSA (second column) and streptavidin (third column). Reproduced with permission from Ref. [36]. Copyright (2008) American Chemical Society. 
(a)

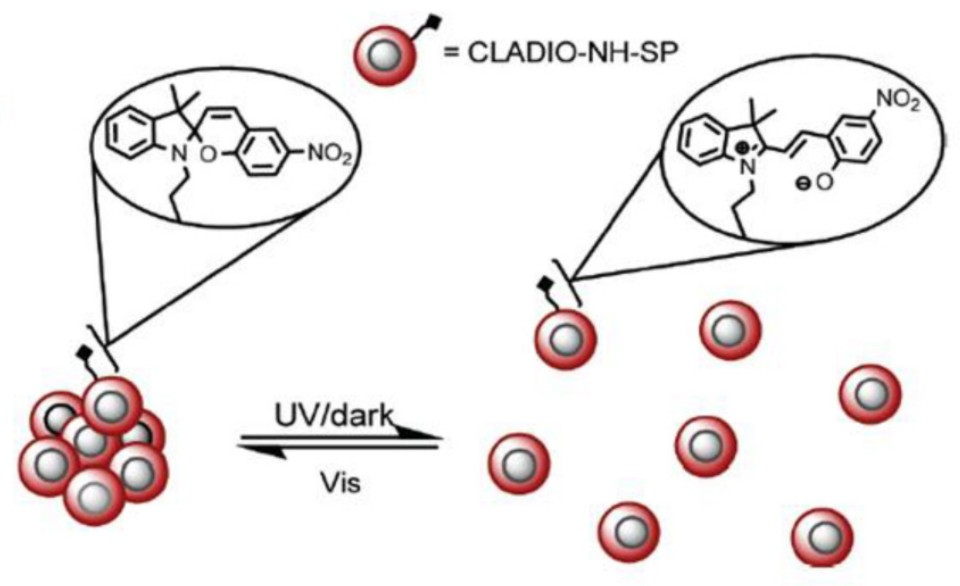

(b)

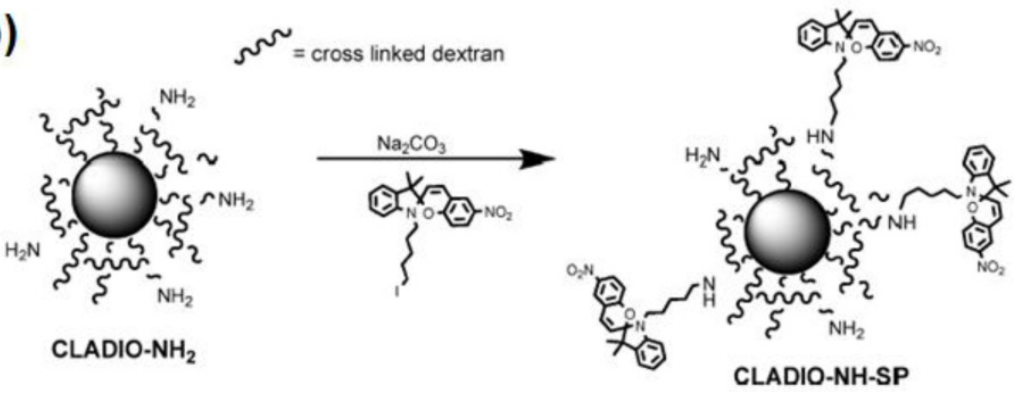

Figure 10. (a) Proposed mechanism of reversible aggregation. (b) Preparation of cross linked dextran sulfate coated iron oxide nanoparticles (CLADIO), functionalized with amine groups and spiropyran (SP). Reproduced with permission with from Ref. [4I]. Copyright (20I0) American Chemical Society.

\section{Bifunctional SPIONs for optical imag- ing and MRI}

Each imaging modality (optical and MRI) has its own strengths and limitations but the strengths of each modality can be combined in bimodal imaging probes to improve the diagnostic quality of tumors. MR offers detailed anatomic imaging while optical imaging provides the real-time molecular targeting of images. SPIONs are generally combined with either quantum dots (e.g. CdSe/ZnS) or fluorescent dyes and used as bimodal magnetic-fluorescent nanoprobes for cell labeling and MRI applications.

\section{I. Quantum dot-conjugated bifunctional SPIONs}

The fluorescent (CdSe QDs) and magnetic $\left(\mathrm{Fe}_{3} \mathrm{O}_{4}\right.$ SPIONs) heterodimers were fabricated in the group of $\mathrm{Xu}$ and were used for the intracellular tracking. Figure 11 details the HRTEM, selected area electron diffraction (SAED), absorption and fluorescence spectra of $\mathrm{Fe}_{3} \mathrm{O}_{4}$-CdSe NPs in hexane solution, and the optical photographs illustrating the fluorescence and magnetic properties [42].

Our group has been actively involved in the synthesis of QDs and magnetic QDs (MQDs) [43-48]. We have successfully demonstrated the magnetic and fluorescent properties of $\mathrm{Fe}_{2} \mathrm{O}_{3}$-CdSe MQDs, silica -coated QDs or MQDs and their application in cell labeling (Figure 12) [43]. The silanization using aminopropyl triethoxysilane (APS) in a reverse microemulsion produced thin silica coating on bare CdSe QDs or $\mathrm{Fe}_{2} \mathrm{O}_{3}-\mathrm{CdSe}$ MQD with surface $\mathrm{NH}_{2}$ groups. The methoxy groups of APS were hydrolyzed and condensed with another APS, exposing surface amine groups on the silanized QDs $\left(\mathrm{SiO}_{2} / \mathrm{QDs}\right)$ for conjugation with oleyl-O-poly(ethyleneglycol)-succinylN-hydroxysuccinimidyl ester, denoted as bio-anchored membrane (BAM). The reaction between the amine group and NHS ester resulted in a covalent amide bond formation, leaving the exposed oleyl group for the effective targeting of cell membrane. The labeling of live cell membranes (HepG2 human liver cancer cells and NIH-3T3 mouse fibroblast cells) using confocal laser scanning microscopy (CLSM) indicated the successful conjugation of silica-coated QDs or MQDs with BAM.

\subsection{Fluorescent dye-conjugated bifunctional SPIONs}

Jeong and coworkers have developed oleyl-chitosan (oleic acid-conjugated chitosan) SPIONs [49]. In aqueous solution, oleyl-chitosan could self-assemble into core-shell structures and provide the core compartment for the loading of SPIONs. Oleyl-chitosan@ SPION showed good enhanced MRI 
sensitivity in MRI. Cy 5.5 dye was functionalized on the oleyl-chitosan for near-infrared (NIR) in vivo optical imaging. SPION-loaded Cy5.5-conjugated oleyl-chitosan NPs were injected intravenously into a tumor-bearing mice. Both NIR fluorescence and MR imaging showed the detectable signal intensity and enhancement in tumor tissues via enhanced permeability and retention (EPR) effect (Figure 13).

Zhang et al. reported PEG coated SPIONs for both MRI and optical imaging. The biocompatible PEG coating bearing amine functional group could serve as a platform to incorporate a variety of targeting, therapeutic or imaging ligands [50]. In this case, chlorotoxin was conjugated to PEG@SPION and Cy5.5 (a near-infrared fluorescent dye). These SPIONs have shown specifically to accumulate in xenograft tumors of a brain tumor mouse model. Furthermore, they did not have any toxicity or negative health effects from the results of histopathology and blood toxicity assays. Huang and coworkers have designed hyaluronic acid (HA) coated SPIONs for targeting activated macrophages [51]. The HA-coated SPIONs had specific biological recognition with the receptor CD44. The cell uptake studies showed a significant uptake of SPIONs by activated macrophage cell line THP-1 and enabled MRI of THP-1 cells. The dual modal probes could be used to track the magnetite core and cargo individually. The magnetite core was only present inside the cells while the cargo fluorescein was found to be delivered to the cell nucleus. This study reveals the fact that the HA-based SPIONs have great potential in nucleus targeting drug delivery.

Howes et al. reported a simple synthesis of multicolored bright fluorescent-magnetic NPs by encapsulating hydrophobic conjugated polymers and SPIONs in phospholipid micelles [52]. These SPIONs were shown to be magnetically responsive and simultaneously fluorescent as bimodal imaging agents. These bifunctional NPs had shorter effect on the transverse $T_{2}{ }^{*}$ relaxation time and yet showed their potential as MRI contrast agent. They were also successfully taken up by SH-SY5Y neuroblastoma cells and showed their potential in fluorescence imaging.
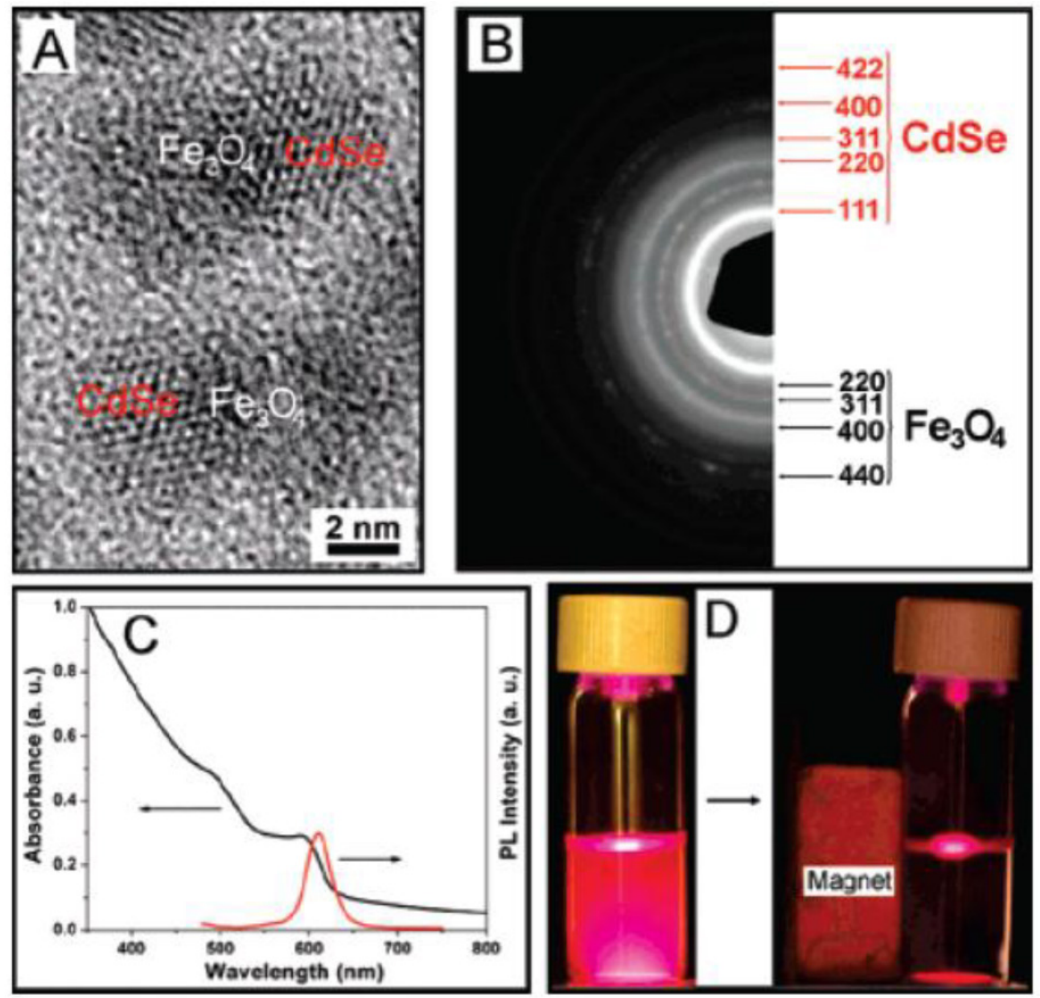

Figure II. (A) HRTEM image and (B) EDP analysis of $\mathrm{Fe}_{3} \mathrm{O}_{4}-\mathrm{CdSe}$ heterodimers. (C) The UV-Vis and fluorescence spectra of $\mathrm{Fe}_{3} \mathrm{O}_{4}-\mathrm{CdSe} \mathrm{NPs}$ in hexane solution. (D) The fluorescence images of the hexane solution of $\mathrm{Fe}_{3} \mathrm{O}_{4}-\mathrm{CdSe} N \mathrm{Ns}$ before and after attraction by a small magnet (excited by a UV lamp, $\lambda$ ex $=365 \mathrm{~nm}$ ). Reproduced with permission from Ref. [42]. Copyright (2008) American Chemical Society. 

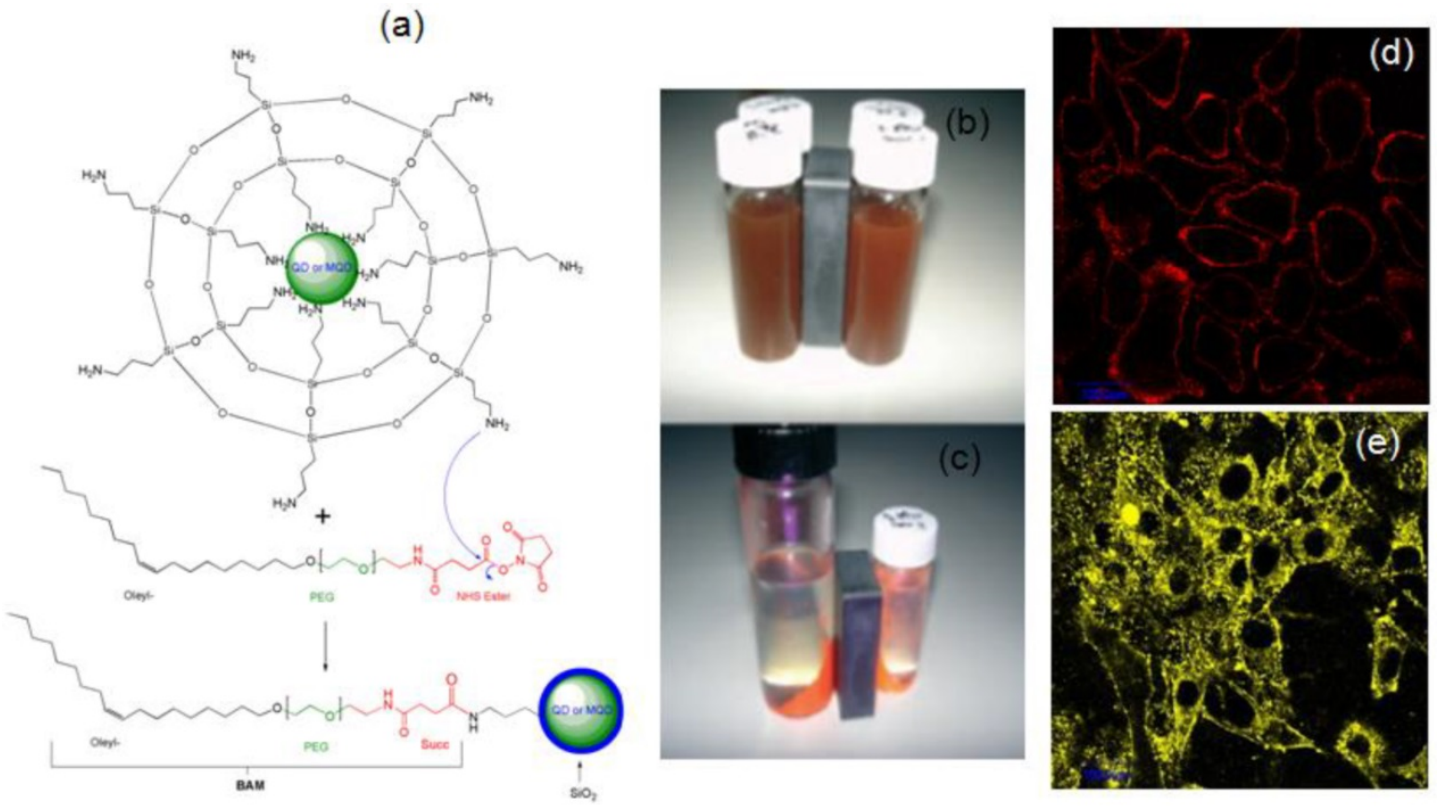

Figure 12. (a) A scheme depicting the silica coating of QDs and MQDs in a reverse microemulsion. (b, c) Photographs of (b) MQDs under white light before magnetic harvesting; (c) Magnetic and fluorescent properties under UV excitation at $365 \mathrm{~nm}$ of harvested red MQDs. (d, e) CLSM images showing the labeling of (d) HepG2 human liver cancer cells and (e) NIH-3T3 mouse fibroblast cells, of cell membranes with BAM-SiO ${ }_{2}-\mathrm{QD}_{\mathrm{S}}$. Reproduced with permission from Ref. [43]. Copyright (2007) Wiley-VCH.
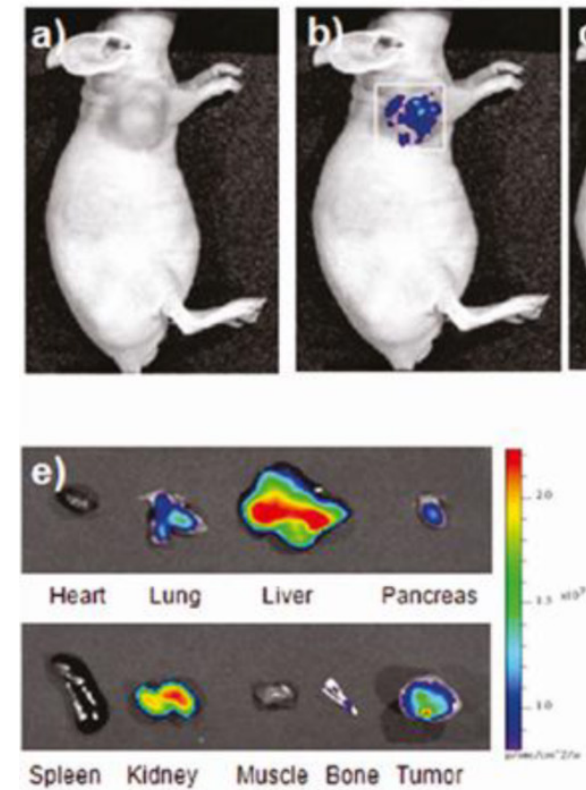
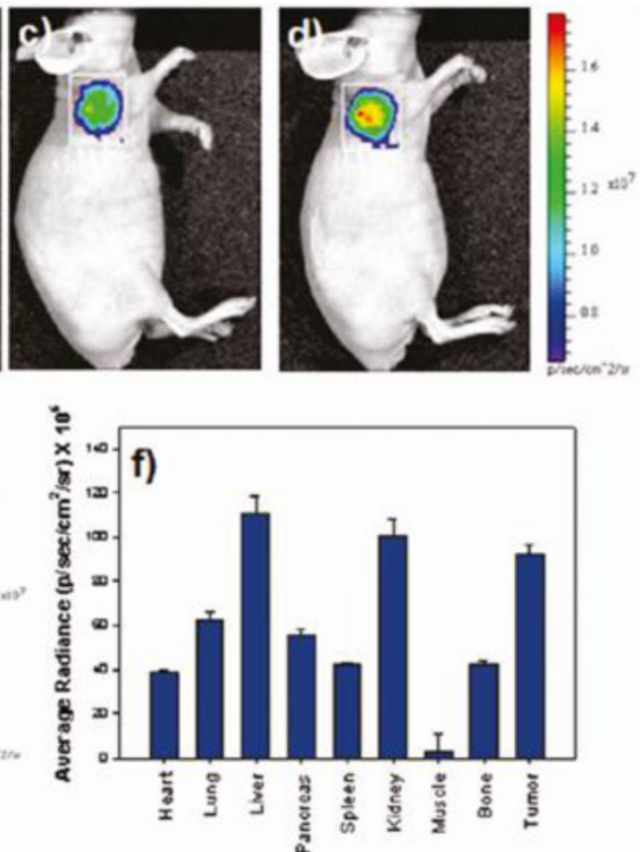

Figure 13. In vivo NIRF images of U87MG-bearing mice. The images were obtained (a) before injection and at (b) Ih, (c) $3 \mathrm{~h}$, and (d) $5 \mathrm{~h}$ after injection of SPION -Cy5.5-oleyl-chitosan NPs. (e) Ex vivo NIRF images of major tissues excised from the mice at $5 \mathrm{~h}$ post injection. (f) A quantification of the ex-vivo tissues was recorded as average radiance $\left(\mathrm{p} / \mathrm{s} / \mathrm{cm}^{2} / \mathrm{sr}\right)$. Reproduced with permission from Ref. [49]. Copyright (201 I) American Chemical Society.

\section{Radionuclides-conjugated MRI/PET nanoprobes}

Positron emission tomography (PET) is a useful tool for whole-body imaging with high detection sensitivity (< picomolar range) and therefore, it provides a high sensitivity metabolic images [53-55]. The combination of MRI/PET has shown the synergistic effect and given the high anatomical spatial resolution of
MRI and the unparalleled sensitivity and functional imaging of PET. Nanoparticles with unique functionality characteristics are well-suited as probes for molecular imaging.

${ }^{18} \mathrm{~F}$ and ${ }^{64} \mathrm{Cu}$ are commonly used as radionuclides in positron emission tomography (PET). Louie and coworkers have developed radionuclide-magnetic dual mode PET/MRI active probes using SPION conjugated with amine-activated DOTA 
(1,4,7,10-tetraazacyclo-dodecane-1,4,7,10-tetraacetic acid) ${ }^{64} \mathrm{Cu}$ (II) for targeting vascular inflammation [56]. Bao and coworkers have developed dual-modality PET/MRI NPs comprising of monocrystalline SPION core coated with PEGylated phospholipids and the chelator, DOTA to allow labeling with positron-emitting ${ }^{64} \mathrm{Cu}$. Radiolabeling with ${ }^{64} \mathrm{Cu}$ at high yield and high purity were achieved. The ${ }^{64} \mathrm{Cu}-\mathrm{SPION}$ probes exhibited strong MRI and PET signals [57].

\section{Multifunctional SPIONs for drug de- livery}

The surface of SPIONs has been modified to incorporate the drugs such as doxorubicin (Dox), one of the clinically approved anticancer drugs for breast cancer. The Pluronic surfactant stabilized oleic acid coated SPIONs were developed as shown in Figure 14
[58]. The water insoluble drug, Dox was loaded into the above SPIONs and released slowly over 2 weeks under in vitro conditions in breast and prostate cancer cell lines. Chen et al. described a method to bind doxorubicin covalently to $\mathrm{Fe}_{3} \mathrm{O}_{4} @ \mathrm{SiO}_{2}$ core-shell NPs via an amide bond, where the active $-\mathrm{COOH}$ group on $\mathrm{NPs}$ reacted with the $-\mathrm{NH}_{2}$ group of Dox molecules [59]. The Dox-loading was $86.5 \%$ and the release behavior was studied under low $\mathrm{pH}$ conditions in the presence of protease. Hyeon and coworkers have developed uniform mesoporous silica NPs (MSN) decorated with dye and multiple magnetite SPIONs for MRI, fluorescence imaging and drug delivery (Figure 15) [60]. This system has successfully enabled the delivery of DOX into the tumor sites, as demonstrated by MR animal imaging.

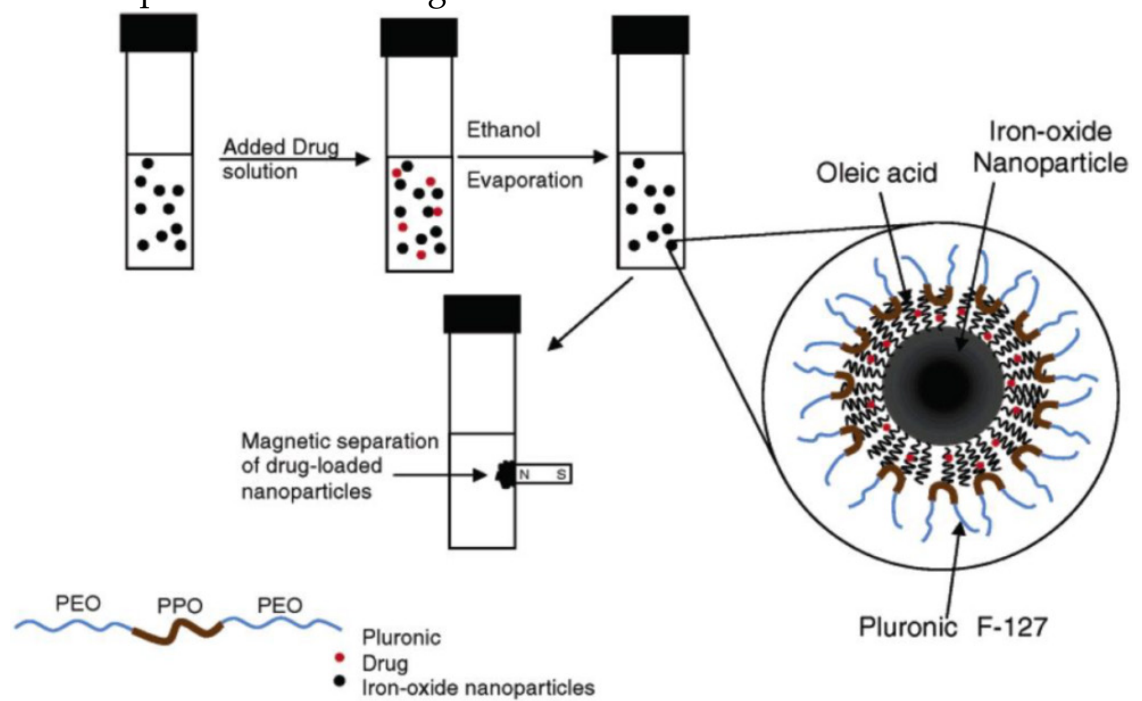

Figure 14. Formulation of SPIONs and the process for drug loading. Reproduced with permission from Ref. [58]. Copyright (2005) American Chemical Society.
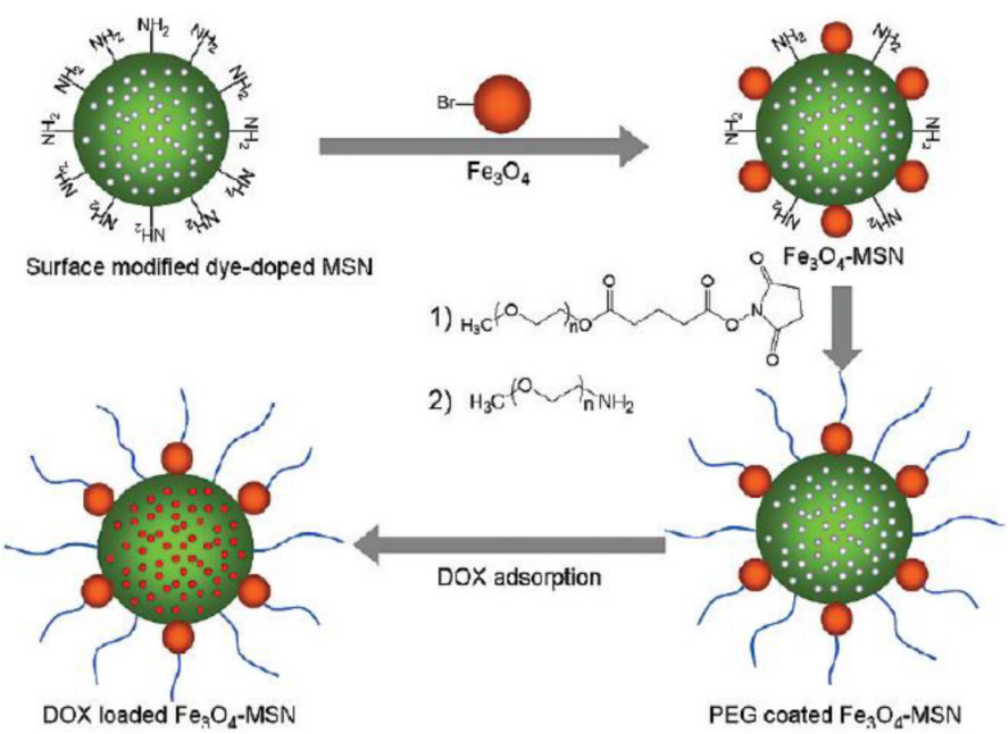

Figure 15. The synthetic procedure for dye-doped mesoporous silica NPs (MSN). Reproduced with permission from Ref. [60]. Copyright (2010) American Chemical Society. 


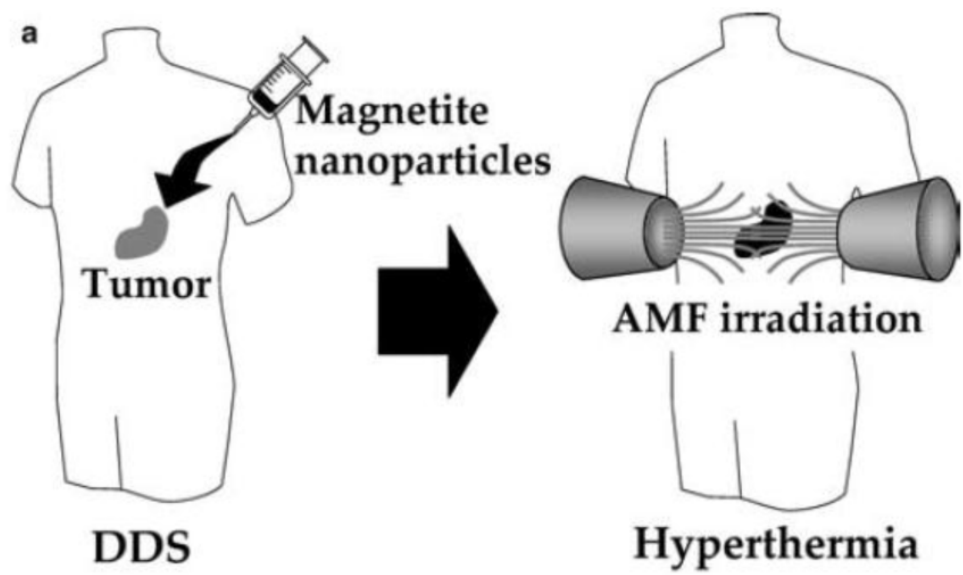

Figure 16. Hyperthermia using magnetite nanoparticles. Scheme of hyperthermia treatment. Magnetite nanoparticles are concentrated in tumor tissue by the DDS. Then the nanoparticles are irradiated with an AMF produced outside the human body, resulting in tumor-specific hyperthermia. Reproduced with permission from Ref. [6I]. Copyright (2005) Springer-Verlag 2005.

\section{Multifunctional SPIONs for Hyper- thermia}

Multifunctional SPIONs have been used in hyperthermia treatment of cancer. Figure 16 [61] shows a schematic of hyperthermia using SPIONs. In this therapy, the NPs are exposed to an oscillating magnetic field ( $\mathrm{kHz}-\mathrm{MHz})$ and heat is generated to kill the tumor cells due to two mechanisms that depend on the size of the particles: a) Brownian modes: for NPs $<100 \mathrm{~nm}$ in diameter (single domain NPs), heat produced due to friction between oscillating particles. b) Neél modes: for larger particles, heat produced due to the rotation of the magnetic moment with each field oscillation [62].

Amphipathic polymer pullulan acetate (PA)-coated SPIONs were prepared for in vitro hyperthermia therapy. The spherical SPIONs had the mean diameter of $25.8 \mathrm{~nm} \pm 6.1 \mathrm{~nm}$. These PA-coated SPIONs had high magnetite content $(51.9 \mathrm{emu} / \mathrm{g}$ saturated magnetization) and also had good biocompatibility. These SPIONs had excellent therapeutic efficacies on KB cells stemming of $56 \%$ and $78 \%$ at 45 ${ }^{\circ} \mathrm{C}$ and $47{ }^{\circ} \mathrm{C}$, respectively [63]. Hong and coworkers had synthesized the $\mathrm{Fe}_{3} \mathrm{O}_{4}$-chitosan NPs for hyperthermia [64]. Baker and coworkers demonstrated the biocompatible phospholipid core/shell-type iron/iron oxide nanocomposite particles for magnetic hyperthermia cancer therapy [65]. The nanocomposites showed more effectiveness in hyperthermia treatment because the heating in an alternating magnetic field was better than iron oxide NPs alone. Zhang and coworkers reported that magnetic cobalt spinel ferrite NPs coated with biocompatible polygalacturonic acid functionalized with ligands could be used for specific in vitro and in vivo targeting of expressed EphA2 receptors on ovarian cancer cells [66].
Folate-conjugated SPIONs were used for solid tumor targeting in specific magnetic hyperthermia mediators [67]. The folate surface of maghemite NPs could recognize the folate receptor and was proven by folate receptor expressing cell lines or by radio-labeled folic acid in competitive binding experiments. Water-dispersible sugar-coated SPIONs were designed as magnetic fluid hyperthermia heat mediators and $T_{2}$ negative contrast agents for MRI [68]. SPIONs of ca. 16-18 nm had good transverse relaxivity and large heat release upon application of radio frequency (RF) electromagnetic radiation with amplitude and frequency close to the human tolerance limit. The authors claimed that these particles could be used as an efficient bifunctional targeting system for theranostic applications. Initially, the hydrophobic oleic acid stabilized SPIONs synthesized via thermal decomposition method were made water soluble by the displacement of the stabilizing agents, and by covalent grafting of the carbohydrate derivatives via the phosphonate function.

Iridium-complex-functionalized $\mathrm{Fe}_{3} \mathrm{O}_{4} / \mathrm{SiO}_{2} \mathrm{NPs}$ were designed for three-in-one system [69]. The iron oxide NPs provided the capability for MRI. The phosphorescent iridium complex made it well suited for phosphorescent labeling and singlet oxygen generation to induce apoptosis of cancer cells.

\section{RNA delivery by nanoparticles}

RNA-based therapeutics such as small interfering RNA (siRNA) and microRNA (miRNA) provide a promising strategy to treat cancer by targeting the specific proteins involved in the mechanism of proliferation, invasion, anti-apoptosis, drug resistance, and metastasis. NPs complexed with polycations and attached to cholesterol groups or conjugated with cell-surface receptors are commonly used for in vivo delivery of therapeutic siRNAs. The cholesterol 
groups can enhance their stability before systemic delivery. Furthermore, the receptor-mediated cell uptake and release by endosomes would enable for the targeted delivery of the siRNAs [70].

\section{I. Small interfering ribonucleic acid (siRNA) delivery}

Cancer cell targeted gene silencing was reported with multifunctional manganese-doped SPIONs for simultaneous delivery and multimodal imaging [71]. The particles were coated with bovine serum albumin (BSA), PEG, and functionalized with RGD peptide (Arg-Gly-Asp) and therapeutic siRNA labeled with Cy5 in all-in-one system. In another interesting work, Moore and coworkers have developed dual-mode imaging probes for in vivo transfer of siRNA and demonstrated the simultaneous imaging of tumors by high-resolution MRI and near-infrared in vivo optical imaging (NIRF) [72]. These probes consisted of dextran-coated SPION labeled with a near-infrared dye, Cy5.5 and covalently linked to siRNA molecules specific for the inhibition of GFP expression. Furthermore, this probe was modified with a membrane translocation peptide, myristoylated polyarginine peptides (MPAP) for intracellular delivery.

\subsection{Micro RNA (miRNA) delivery by nano- particles}

Targeted delivery of RNA-based therapeutics for cancer therapy remains a challenge. Huang and coworkers have developed a NP formulation based on liposome-polycation-hyaluronic acid (LPH). These NPs have been modified with tumor-targeting single-chain antibody fragment ( $\mathrm{scFv}$ ) and used for systemic delivery of small interfering RNA (siRNA) and microRNA (miRNA) into experimental lung metastasis of murine B16F10 melanoma. The tumor growth was found to be inhibited by NPs containing siRNA and miRNA [73]. Wang and coworkers have devel-

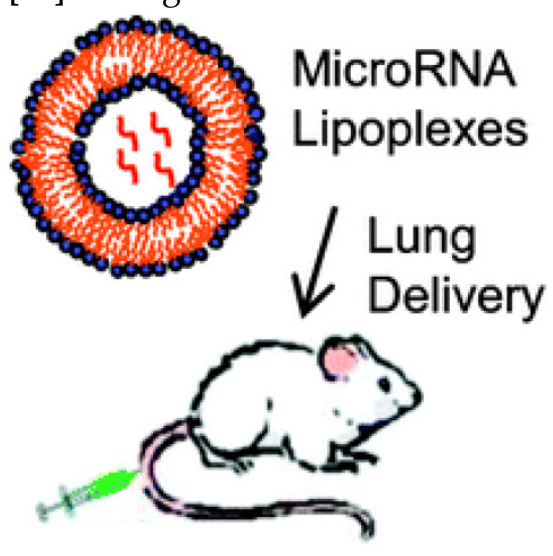

oped PEGylated LPH NP formulation modified with cyclic RGD peptide (cRGD) for specific and efficient delivery of miRNA or its anti-miRNA antisense oligonucleotides (AMOs) into endothelial cells, targeting $\alpha_{v} \beta_{3}$ integrin present on the tumor neovasculature. They have also demonstrated that cRGD modified LPH NPs have potential in miRNA therapeutics for anti-angiogenesis [74].

While the importance of microRNAs (miRNAs) in cancer treatment or manipulation of genetic expression has been increasingly recognized for developing miRNA-based therapies, the controlled delivery of miRNAs into specific cells constitutes a challenging task. Lung cancer is the leading cause of cancer deaths in western countries and several studies demonstrated that miRNAs are actively involved in tumor development by serving as tumor suppressors, oncogenes or both. In lung cancer, miRNAs may serve as both diagnostic and prognostic biomarkers as well as regulate in vitro and in vivo tumor progression. However, miRNA-based therapy is faced with several challenges including lack of tissue specificity, lack of optimal delivery systems, poor cellular uptake and risk of systemic toxicity. Lee and coworkers reported a cationic lipoplexes based miRNA delivery system for the development of miRNA-based therapeutics in lung cancer treatment (Figure 17) [75].

Recently, cell transfection studies on miRNA-AuNPs have demonstrated the efficient gene knockdown in the functional luciferase assay and their potential in biosensing or targeting (Figure 18) [76]. The surface chemistry of Au NPs can dictate the cellular uptake. In a recent study, RNA-AuNP caused no significant changes in gene expression, cell cycle progression, or apoptosis induction in HeLa cells [77]. We believe that the miRNA-AuNP could be taken up by the receptor-mediated endocytosis and Au NPs released by endosomes.

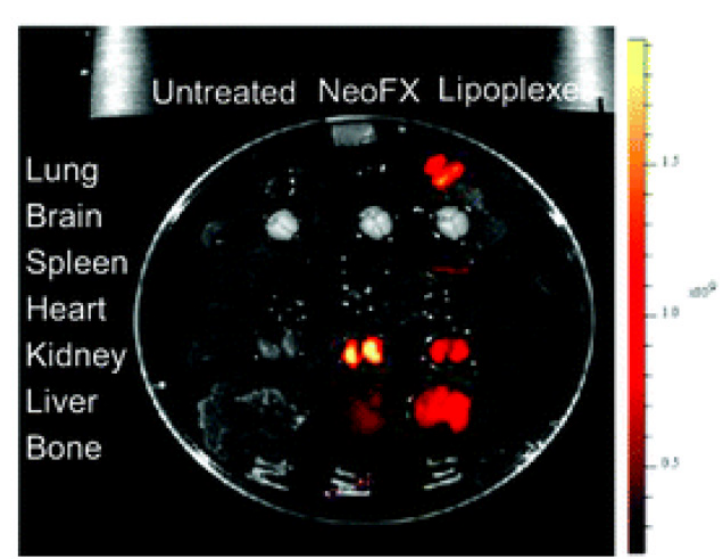

Figure 17. (Left) A scheme depicting miRNA-cationic lipoplexes for lung cancer delivery. (Right) Tissue distribution of Cy5-G3I39 containing lipoplexes and Cy5-G3 139 NeoFX complexes. $4 \mathrm{~h}$ after intravenous administration, tissues were harvested and then Cy5 fluorescence signals measured. A typical Cy5 fluorescence images of whole tissues. Note: Cy5-G3 139: Cy5 dye labeled oligodeoxynucleotides (Cy5-G3 I39, 5'-Cy5-TCT CCC AGC GTG CGC CAT-3') and NeoFX: a transfection agent. Reprinted with permission from Ref. [75]. Copyright (2011) American Chemical Society. 


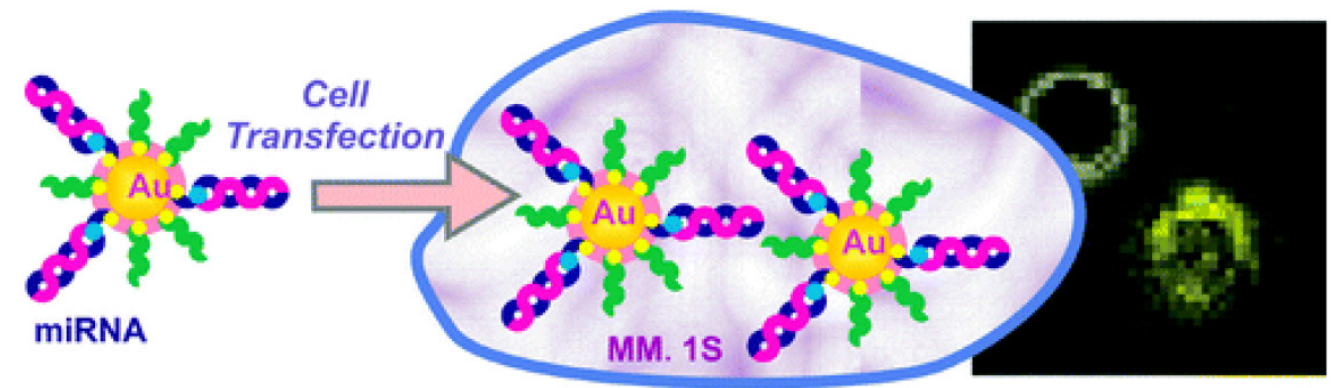

Figure 18. Illustration of the preparation of miRNA-AuNP conjugates for delivering miRNAs to cells where miRNA is labeled with fluorescent dyes (e.g., Cy3 or Cy5). Reprinted with permission from Ref. [76]. Copyright (2012) American Chemical Society.

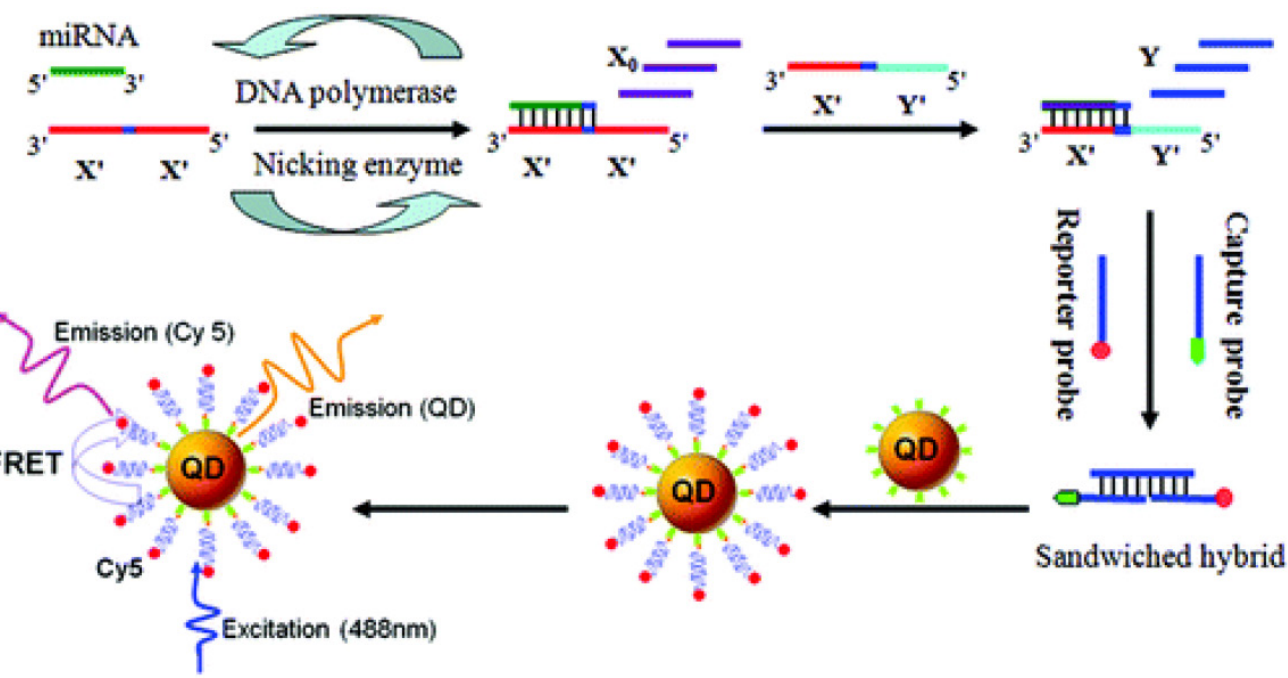

Figure 19. Scheme of the miRNA assay based on the two-stage EXPAR and single-QD-based nanosensor. Reprinted with permission from Ref. [78]. Copyright (2012) American Chemical Society.

MicroRNAs (miRNAs) play important roles in a wide range of biological processes, and their aberrant expressions are associated with various diseases. Highly sensitive and specific miRNA detection method based on the two-stage exponential amplification reaction (EXPAR) and a single QD (Streptavidin-coated $605 \mathrm{~nm}$ emission) -based nanosensor, has recently been developed (Figure 19) [78]. In comparison with conventional PCR with the involvement of thermal cycling, EXPAR offers the following advantages: a) proceeds at a constant temperature; b) provides high amplification efficiency, which can rapidly amplify short oligonucleotides (106 $-10^{9}$-fold) within minutes and c) a detection limit of as low as 0.1 $\mathrm{aM}$ and can even discriminate single-nucleotide differences between miRNA family.

Cheng et al. have shown that biodegradable polymer NPs, which are coated with cell-penetrating peptides CPP, nona-arginine (ARG), can effectively deliver chemically modified oligonucleotide analogues to cancer cells to achieve therapeutic miRNA inhibition or alternative splicing. (Figure 20) [79]. This NP system could block the activity of the oncogenic miRNA, miR-155, as well as modulate splicing to attenuate the expression of the proto-oncogene, Mcl-1.
Regulation of these genes in human cancer cells reduced cell viability and produced pro-apoptotic effects. These findings establish polymer NPs as delivery vectors for nonconventional forms of gene therapy, which have strong therapeutic implications.

\section{Conclusions and perspectives}

In this review, we have discussed the uses of multifunctional SPIONs for theranostics applications. The different functionalities of NPs would enable the macroscopic (magnetic resonance) and microscopic (fluorescence) imaging of target cells. The integration of multi- functionalities into a single system would be highly useful for MRI/PET/optical/PDT multimodality imaging and therapy. This system may be suitable for concurrent diagnostic and therapeutic applications.

The uses of SPIONs in the area of different drug delivery approaches are indispensable. The clinically approved drugs for breast cancer are doxorubicin and paclitaxel based NP conjugates. Recently, many strategies have been developed to treat cancer by targeting the tumors with gene delivery vehicles such as siRNA, miRNA which have proven to control the tumors. 


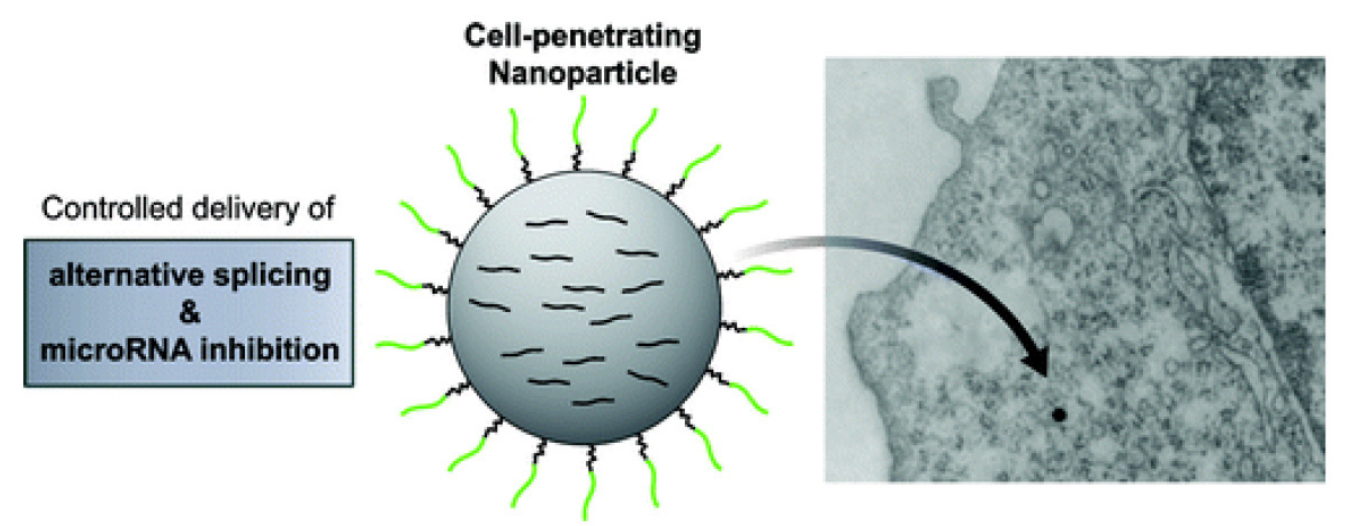

Figure 20. Controlled delivery of alternative splicing and miRNA inhibition induced by nona-arginine-coated NPs. ARG-NPs comprise a spherical PLGA core coated with PEGylated ARG. The intracellular uptake of osmium tetroxide-loaded ARG-NPs was visualized by TEM. scale bars for SEM and TEM micrographs represent I $\mu \mathrm{m}$. Reprinted with permission from Ref. [79]. Copyright (2012) American Chemical Society.

Although considerable progress has been made in recent years, the targeted delivery to cancer tumors without affecting the normal cells remains elusive. The judicious combination of NPs with cancer targeting ligands or immunoconjugates would pave the way for an effective therapy. In this regard, more attention has to be devoted on the development of newer drug delivery approaches, employing these multifunctional SPIONs and/or a novel NP formulation containing miRNA. Using $\mathrm{Au}$ or $\mathrm{QD}$ and/or other polymer NPs, highly sensitive and specific miRNA detection would be possible.

Photodynamic therapy (PDT) is another emerging area in cancer research where the uses of up-conversion NPs, QDs and coated NPs with SPIONs are indispensable. The translational research on cancer depends highly on smarter delivery vehicles discussed above without compromising the damage to the normal cells and tissues.

\section{Acknowledgements}

STS acknowledges the support from the A*STAR (Agency for Science, Technology and Research) Singapore, Joint Council Office (JCO) Grant No. JCOAG03_FG03_2009, and Science Engineering Research Council (SERC) Biomedical Engineering Program (BEP) Grant No. 103149 0011. PP acknowledges the support from the LKC School of Medicine, NTU Singapore.

\section{Competing Interests}

The authors have declared that no competing interest exists.

\section{References}

1. Jun YW, Seo JW, Cheon J. Nanoscaling laws of magnetic nanoparticles and their applicabilities in biomedical science. Acc. Chem. Res. 2008; 41: 179-89.

2. Cheon J, Lee JH. Synergistically integrated nanoparticles as multimodal probes for nanobiotechnology. Acc. Chem. Res. 2008; 41: 1630-40.

3. Laurent S, Forge D, Port M, Roch A, Robic C, Vander Elst L, Muller RN. Magnetic iron oxide nanoparticles: synthesis, stabilization, vectorization, physicochemical characterizations, and biological application. Chem. Rev. 2008; 108: 2064-110.

4. $\mathrm{Xu} \mathrm{C}$, Sun S. Superparamagnetic nanoparticles as targeted probes for diagnostic and therapeutic applications. Dalton Trans. 2009; 29: 5583-91.

5. Ge S, Shi X, Sun K, Li C, Uher C, Baker JR, Banaszak MM, Orr BG. Facile hydrothermal synthesis of iron oxide nanoparticles with tunable magnetic properties. J. Phys. Chem. C 2009; 113: 13593-99.

6. Verges MA, Costo R, Roca AG, Marco JF, Goya GF, Serna CJ, Morales MP. Uniform and water stable magnetite nanoparticles with diameters around the monodomain-multidomain limit. J. Phys. D: Appl Phys 2008; 41: 134003.

7. Qiao R, Yang C, Gao M. Superparamagnetic iron oxide nanoparticles: from preparations to in vivo MRI applications. J. Mater. Chem. 2009; 19: 6274-93.

8. Yu M K, Park J, Jon S. Targeting strategies for multifunctional nanoparticles in cancer imaging and therapy. Theranostics 2012; 2: 3-44.

9. Hildebrandt N, Hermsdorf D, Signorell R, Schmitz SA, Diederichsen U. Superparamagnetic iron oxide nanoparticles functionalized with peptides by electrostatic interactions. ARKIVOC 2007;:79-90.

10. Josephson L, Tung C-H, Moore A, Weissleder R. High-efficiency intracellular magnetic labeling with novel superparamagnetic-tat peptide conjugates. Bioconj. Chem. 1999; 10: 186-91.

11. Schellenberger E, Rudloff F, Warmuth C, Taupitz M, Hamm B, Schnorr J, Protease-Specific Nanosensors for Magnetic Resonance Imaging. Bioconj. Chem. 2008; 19: 2440-45.

12. Xie J, Chen K, Lee H, Xu C, Hsu AR, Peng S, Chen X, Sun S. Ultrasmall $\mathrm{c}(\mathrm{RGDyK})$-coated $\mathrm{Fe}_{3} \mathrm{O}_{4}$ nanoparticles and their specific targeting to integrin $\alpha_{v} \beta_{3}$-rich tumor cells. J. Am. Chem. Soc. 2008; 130: 7542-3.

13. Puertas S, Batalla P, Moros M, Polo E, Pino P, Guisán JM, Grazú V, Fuente JM. Taking advantage of unspecific interactions to produce highly active magnetic nanoparticle-antibody conjugates. ACS Nano 2011; 5: 4521-4528.

14. Xu H, Aguilar ZP, Yang L, Kuang M, Duan H, Xiong Y, Wei H, Wang A. Antibody conjugated magnetic iron oxide nanoparticles for cancer cell separation in fresh whole blood. Biomaterials 2011; 32: 9758-9765.

15. Huh Y, Jun Y, Song H, Kim S, Choi J, Lee J, Yoon S, Kim K, Shin J, Suh J, Cheon $\mathrm{J}$. In vivo magnetic resonance detection of cancer by using multifunctional magnetic nanocrystals. J. Am. Chem. Soc. 2005; 127: 12387-91.

16. Song E-O, Hu J, Wen C-Y, Tian Z-Q, Yu X, Zhang Z-L, Shi Y-B, Pang D-W. Fluorescent-magnetic-biotargeting multifunctional nanobioprobes for detecting and isolating multiple types of tumor cells. ACS Nano 2011; 5: 761-70.

17. Thunemann, AF, Schutt D, Kaufner L, Pison U, Mohwald H. Maghemite nanoparticles protectively coated with poly(ethylene imine) and poly(ethylene oxide)-block-poly(glutamic acid). Langmuir 2006; 22: 2351-2357.

18. Veiseh O, Sun C, Gunn J, Kohler N, Gabikian P, Lee D, Bhattarai N, Ellenbogen R, Sze R, Hallahan A, Olson J, Zhang M. Optical and MRI multifunctional nanoprobe for targeting gliomas. Nano Lett. 2005; 5: 1003-1008.

19. Narain R, Gonzales M, Hoffman AS, Stayton PS, Krishnan KM. Synthesis of monodisperse biotinylated $\mathrm{p}(\mathrm{NIPAAM})$-coated iron oxide magnetic nanoparticles and their bioconjugation to streptavidin. Langmuir 2007; 23: 6299-6304.

20. Isojima T, Lattaada M, Sande JBV, Hatton TA. Reversible clustering of $\mathrm{pH}$ - and temperature-responsive Janus magnetic nanoparticles. ACS Nano 2008; 2: 1799-806.

21. Corr SA, Byrne SJ, Tekoriute R, Meledandri CJ, Brougham DF, Lynch M, Kerskens C, O'Dwyer L, Gun'ko YK. Linear assemblies of magnetic nanoparticles as MRI contrast agents. J. Am. Chem. Soc. 2008; 130: 4214-5.

22. El-Boubbou K, Zhu DC, Vasileiou C, Borhan B, Prosperi D, Li W, Huang X. Magnetic glycol-nanoparticles: A tool to detect, differentiate and unlock the glyco-codes of cancer via magnetic resonance imaging. J. Am. Chem. Soc. 2010; 132: 4490-9.

23. Kim BH, Lee N, Kim H, Am K, Park YI, Choi Y, Shin K, Lee Y, Kwon SG, Na HB, Park J-G, Ahn T-Y, Kim Y-W, Moon WK, Choi SH, Hyeon T. Large-scale synthesis of uniform and extremely small-sized iron oxide nanoparticles for 
high-resolution $T_{1}$ magnetic resonance imaging contrast agents. J. Am. Chem. Soc. 2011; 133: 12624-31.

24. Berret J-F, Schonbeck N, Gazeau F, Kharrat DE, Sandre O, Vacher A, Airiau M. Controlled clustering of superparamagnetic nanoparticles using block copolymers: design of new contrast agents for magnetic resonance imaging. J. Am. Chem. Soc. 2006; 128:1755-61.

25. Babić M, Horák D, Jendelová P, Glogarová K, Herynek V, Trchová M, Likavćanová K, Lesný P, Pollert E, Hájek M, Syková E. Poly(N, $\mathrm{N}$-dimethylacrylamide)-coated maghemite nanoparticles for stem cell labeling. Bioconjugate Chem. 2009; 20: 283-94.

26. Lee $\mathrm{H}$, Lee E, Kim DK, Jang NK, Jeong YY, Jon S. Antibiofouling polymer-coated superparamagnetic iron oxide nanoparticles as potential magnetic resonance contrast agents for in vivo cancer imaging. J. Am. Chem. Soc. 2006; 128: 7383-9.

27. Valero E, Tambalo S, Marzola P, Ortega-Muńoz M, López-Jaramillo FJ, Santayo-González F, López JdD, Delgado JJ, Calvino JJ, Cuesta R, Domínguez-Vera JM, Gálvez N. Magnetic nanoparticles-templated assembly of protein subunits: a new platform for carbohydrate-based MRI nanoprobes. J. Am. Chem. Soc. 2011; 133: 4889-95.

28. Liu L-H, Dietsch H, Schurtenberger P, Yan M. Photoinitiated coupling of unmodified monosaccharides to iron oxide nanoparticles for sensing proteins and bacteria. Bioconjugate Chem 2009; 20: 1349-55.

29. Bamrungsap S, Chen T, Shukoor MI, Chen Z, Sefah K, Chen Y, Tan W. Pattern recognition of cancer cells using aptamer-conjugated magnetic nanoparticles. ACS Nano 2012; 6: 3974-3981.

30. Medley CD, Bamrungsap S, Tan W, Smith JE. Aptamer-conjugated nanoparticles for cancer cell detection. Anal. Chem. 2011; 83: 727-734.

31. Smith JE, Medley CD, Tang Z, Shangguan D, Lofton C, Tan W. Aptamer-conjugated nanoparticles for the collection and detection of multiple cancer cells. Anal. Chem. 2007; 79: 3075-3082.

32. Fan Z, Shelton M, Singh AK, Senapati D, Khan SA, Ray PC. Multifunctional plasmonic shell-magnetic core nanoparticles for targeted diagnostics, isolation, and photothermal destruction of tumor cells. ACS Nano 2012; 6: 1065-1073.

33. Yu MK, Kim D, Lee IH, So JS, Jeong YY, Jon S. Image-guided prostate cancer therapy using aptamer-functionalized thermally cross-linked superparamagnetic iron oxide nanoparticles. Small 2011; 7: 2241-2249.

34. Wang AZ, Bagalkot V, Gu F, Alexis F, Vasilliou C, Cima M, Jon S, Farokhzad O, Novel targeted aptamer-superparamagnetic iron oxide nanoparticle bioconjugates for combined prostate cancer imaging and therapy. Int. J. Radiat. Oncol. Biol Phys. 2007; 69: S110-1.

35. Yigit MV, Mazumdar D, Kim HK, Lee JH, Odintsov B, Lu Y. Smart "turn-on" magnetic resonance contrast agents based on aptamer-functionalized superparamagnetic iron oxide nanoparticles. Chem Bio Chem 2007; 8: 1675-1678.

36. Yigit MV, Mazumdar D, Lu Y. MRI detection of thrombin with aptamer functionalized superparamagnetic iron oxide nanoparticles. Bioconjugate Chem. 2008; 19: 412-7.

37. Kinsella JM, Ivanisevic A. Enzymatic clipping of DNA wires coated with magnetic nanoparticles. J. Am. Chem. Soc. 2005; 127: 3276-7.

38. Chen Z, Hong G, Wang H, Welsher K, Tabakman SM, Sherlock SP, Robinson JT, Liang Y, Dai H. Graphite-coated magnetic nanoparticle microarray for few-cells enrichment and detection. ACS Nano 2012; 6: 1094-1101.

39. Antonietti M, Kuang D, Smarsly B, Zhou Y. Ionic liquids for the convenient synthesis of functional nanoparticles and other inorganic nanostructures. Angew. Chem. Int. Ed. 2004; 43: 4988-92.

40. Tesfai A, El-Zahab B, Kelley AT, Li M, Garno JC, Baker GA, Warner IM. Magnetic and nonmagnetic nanoparticles from a group of uniform materials based on organic salts. ACS Nano 2009; 3: 3244-50.

41. Osborne EA, Jarrett BR, Tu C, Louie AY. Modulation of T2 relaxation time by light-induced, reversible aggregation of magnetic nanoparticles. J. Am. Chem. Soc. 2010; 132: 5934-5.

42. Gao I, Zhang W, Huang P, Zhang B, Zhang X, Xu B. Intracellular spatial control of fluorescent magnetic nanoparticles. J. Am. Chem. Soc. 2008; 130: 3710-1.

43. Selvan ST, Patra PK, Ang CY, Ying JK. Synthesis of silica-coated semiconductor and magnetic quantum dots and their use in the imaging of live cells. Angew. Chem. Int. Ed. 2007; 46: 2448-52.

44. Yi DK, Selvan ST, Lee SS, Papaefthymiou GC, Kundaliya D, Ying JY. Silica-coated nanocomposites of magnetic nanoparticles and quantum dots. J. Am. Chem. Soc. 2005; 127: 4990-1.

45. Ang CY, Giam L, Chan ZM, Lin AWH, Gu H, Devlin E, Papaefthymiou GC, Selvan ST, Ying JY. Facile synthesis of $\mathrm{Fe}_{2} \mathrm{O}_{3}$ nanocrystals without $\mathrm{Fe}(\mathrm{CO})_{5}$ precursor and one-pot synthesis of highly fluorescent $\mathrm{Fe}_{2} \mathrm{O}_{3}-\mathrm{CdSe}$ nanocomposites. Adv. Mater. 2009; 21: 869-73.

46. Lin AWH, Ang CY, Patra PK, Han Y, Gu H, LeBreton JM, Juraszek J, Chiron H, Papaefthymiou GC, Selvan ST, Ying JY. Seed-mediated synthesis, properties and application of $\mathrm{\gamma}^{-} \mathrm{Fe}_{2} \mathrm{O}_{3}-\mathrm{CdSe}$ magnetic quantum dots. J. Solid State Chem. 2011; 184: 2150-8.

47. Janczewski D, Zhang Y, Das GK, Yi DK, Padmanabhan P, Bhakoo KK, Tan TTY, Selvan ST. Bimodal magnetic - fluorescent probes for bio-imaging. Micros. Res. Tech. 2011; 74: 563-76.

48. Selvan ST, Tan TTY, Yi DK, Jana NR. Functional and multifunctional nanoparticles for bioimaging and biosensing. Langmuir 2010; 26: 11631-41.

49. Lee C-M, Jang DR, Kim J, Cheong S-J, Kim E-M, Jeong M-H, Kim S-H, Kim DW, Lim ST, Sohn M-H, Jeong YY, Jeong H-J. Oleyl-chitosan nanoparticles based on a dual probe for optical/MR imaging in vivo. Bioconjugate Chem. 2011; 22: 186-92

50. Sun C, Kim D, Fang C, Bhattarai N, Veiseh O, Kievit F, Stephen Z, Lee D, Ellenbogen RG, Ratner B, Zhang M. PEG-mediated synthesis of highly dispersive multifunctional superparamagnetic nanoparticles: their physicochemical properties and function in vivo. ACS Nano 2010; 4: 2402-10.

51. Kamat M, El-Boubbou K, Zhu DC, Lansdell T, Lu X, Li W, Huang X. Hyaluronic acid immobilized magnetic nanoparticles for active targeting and imaging of macrophages. Bioconjugate Chem. 2010; 21: 2128-35.

52. Howes P, Green M, Bowers A, Parker D, Varma G, Kallumadil M, Hughes M, Warley A, Brain A, Botnar R. Magnetic conjugated polymer nanoparticles as bimodal imaging agents. J. Am. Chem. Soc. 2010; 132: 9833-42.

53. Cherry SR. Multimodality imaging: beyong PET/CT and SPECT/CT. Semin. Nucl. Med. 2009; 39: 348-353

54. Zhou J, Yu M, Sun Y, Zhang X, Zhu X, Wu Z, Wu D, Li F. Fluorine-18-labeled Gd3+/Yb3+/Er3+ co-doped NaYF4 nanophosphors for multimodality PET/MR/UCL imaging. Biomaterials, 2011; 32: 1148-1156.

55. Berti V, Osorio RS, Mosconi L, Li Y, De Santi S, de Leon MJ. Early detection of Alzheimer's disease with PET imaging. Neurodegener. Dis. 2010; 7: 131-135.

56. Jarett BR, Gustafsson B, Kukis DL, Louie AY. Synthesis of ${ }^{64} \mathrm{Cu}$-labeled magnetic nanoparticles for multimodal imaging. Bioconjugate Chem. 2008; 19: 1496-1504.

57. Glaus C, Rossin R, Welch MJ, Bao G. In vivo evaluation of ${ }^{64} \mathrm{Cu}$-labeled magnetic nanoparticles as a dual-modality PET/MR imaging agent. Bioconjugate Chem. 2010; 21: 715-22.

58. Jain TK, Morales MA, Sahoo SK, Leslie-Pelecky DL, Labhasetwar V. Iron oxide nanoparticles for sustained delivery of anticancer agents. Mol. Pharmaceutics 2005; 2: 194-205.

59. Chen $\mathrm{FH}, \mathrm{Gao} \mathrm{Q}, \mathrm{Ni} \mathrm{JZ}$. The grafting and release behavior of doxorubincin from $\mathrm{Fe}_{3} \mathrm{O}_{4} @ \mathrm{SiO}_{2}$ core-shell structure nanoparticles via an acid cleaving amide bond: the potential for magnetic targeting drug delivery. Nanotechnology 2008; 19: 165103

60. Lee JE, Lee N, Kim H, Kim J, Choi SH, Kim JH, Kim T, Song IC, Park SP, Moon WK, Hyeon T. Uniform mesoporous dye-doped silica nanoparticles decorated with multiple magnetite nanocrystals for simultaneous enchanced magnetic resonance imaging, fluorescence imaging and drug delivery. J. Am. Chem. Soc. 2010; 132: 552-7.

61. Ito A, Honda H, Kobayashi T. Cancer immunotherapy based on intracellular hyperthermia using magnetite nanoparticles: a novel concept of "heat-controlled necrosis" with heat shock protein expression. Cancer Immunol Immunother. 2006; 55: 320-28.

62. Cherukuri P, Glazer ES, Curley SA. Targeted hyperthermia using metal nanoparticles. Adv. Drug Deliver. Rev. 2010; 62: 339-45.

63. Gao F, Cai Y, Zhou J, Xie X, Ouyang W, Zhang Y, Wang X, Zhang X, Wang X, Zhao L, Tang J. Pullulan acetate coated magnetite nanoparticles for hyperthermia: preparation, characterization and in vitro experiments. Nano Res. 2010; 3: 23-31.

64. $\mathrm{Qu}$ J, Liu G, Wang Y, Hong R. Preparation of $\mathrm{Fe}_{3} \mathrm{O}_{4}$-chitosan nanoparticles used for hyperthermia. Adv. Powder Technol. 2010; 21: 461-7.

65. Zhang G, Liao Y, Baker I. Surface engineering of core/shell iron/iron oxide nanoparticles from microemulsions for hyperthermia. Mater. Sci. Eng. C 2010; 30: 92

66. Scarberry KE, Dickerson EB, McDonald JF, Zhang ZJ. Magnetic nanoparticle-peptide conjugates for in vitro and in vivo targeting and extraction of cancer cells. J. Am. Chem. Soc. 2008; 130: 10258-62.

67. Sonvico F, Mornet S, Vasseur S, Dubernet C, Jaillard D, Degrouard J, Hoebeke J, Duguet E, Colombo P, Couvreur P. Folate-conjugated iron oxide nanoparticles for solid tumor targeting as potential specific magnetic hyperthermia mediators: Synthesis, physicochemical characterization, and in vitro experiments. Bioconj. Chem. 2005; 16: 1181-8

68. Lartigue L, Innocenti C, Kalaivani T, Awwad A, Duque MdMs, Guari $\mathrm{Y}$, Larionova J, Guérin C, Montero J-LG, Barragan-Montero V, Arosio P, Lascialfari A, Gatteschi D, Sangregorio C. Water-dispersible sugar-coated iron oxide nanoparticles. An Evaluation of their relaxometric and magnetic hyperthermia properties. J. Am. Chem. Soc. 2011; 133: 10459-72.

69. Lai C, Wang Y, Lai C, Yang M, Chen C, Chou P, Chan C, Chi Y, Chen Y, Hsiao J. Iridium-complex-functionalized $\mathrm{Fe}_{3} \mathrm{O}_{4} / \mathrm{SiO}_{2}$ Core/Shell nanoparticles: a facile three-in-one system in magnetic resonance imaging, luminescence imaging, and photodynamic therapy. Small 2008; 4: 218-24.

70. Castanotto D, Rossi JJ. The promises and pitfalls of RNA-interference-based therapeutics. Nature 2009; 457: 426-33.

71. Lee $\mathrm{JH}$, Lee $\mathrm{K}$, Moon $\mathrm{SH}$, Lee $\mathrm{Y}$, Park TG, Cheon J. All-in-one target-cell-specific magnetic nanoparticles for simultaneous molecular imaging and siRNA delivery. Angew Chem Int. Ed. 2009; 48: 4174-9.

72. Medarova Z, Pham W, Farrar C, Petkova V, Moore A. In vivo imaging of siRNA delivery and silencing in tumors. Nat. Med. 2007; 13: 372-7.

73. Chen Y, Zhu X, Zhang X, Liu B, Huang L. Nanoparticles modified with tumor-targeting scFv deliver siRNA and miRNA for cancer therapy. Molecular Therapy 2010; 18: 1650-6.

74. Liu X.-Q, Song W.-J, Sun T.-M, Zhang P.-Z, Wang J. Targeted delivery of antisense inhibitor of miRNA for antiangiogenesis therapy using cRGD-functionalized nanoparticles. Mol. Pharmaceutics 2011, 8: 250-9.

75. Wu Y, Crawford M, Yu B, Mao Y, Nana-Sinkam SP, Lee LJ. MicroRNA delivery by cationic lipoplexes for lung cancer therapy. Mol. Pharmaceutics, 2011, 8: $1381-9$. 
76. Crew E, Rahman S, Razzak-Jaffar A, Mott D, Kamundi M, Yu G, Tchah N, Lee J, Bellavia M, Zhong C.-J. MicroRNA conjugated gold nanoparticles and cell transfection. Anal. Chem. 2012, 84: 26-9.

77. Massich MD, Giljohann DA, Schmucker AL, Patel PC, Mirkin CA. Cellular response of polyvalent oligonucleotide-gold nanoparticle conjugates. ACS Nano 2010, 4: 5641-6.

78. Zhang $\mathrm{Y}$, Zhang $\mathrm{C}$. Sensitive detection of microRNA with isothermal amplification and a single-quantum-dot-based nanosensor. Anal. Chem. 2012, 84: 224-31.

79. Cheng CI, Saltzman WM. Polymer nanoparticle-mediated delivery of microRNA inhibition and alternative splicing. Mol. Pharmaceutics, 2012, 9: $1481-8$ 